\title{
Aptitud sobrevenida tras incapacidad laboral prolongada por cáncer
}

\section{Supervening Ability after Prolonged Work Incapacity due to Cancer}

\author{
José Manuel Vicente Pardo', Araceli López-Guillén García²
}

1. Unidad Médica Equipo Valoración Incapacidades. Instituto Nacional de la Seguridad Social. Gipuzkoa. España. Cátedra. Medicina Evaluadora y Pericial UCAM. España.

2. Unidad Médica Equipo Valoración Incapacidades. Instituło Nacional de la Seguridad Social. Murcia. España. Cátedra Medicina Evaluadora y Pericial UCAM. España.

Recibido: 20-05-2019

Aceptado: 28-05-2019

\section{Correspondencia}

José Manuel Vicente Pardo

Correo electrónico: josemanuvicente@gmail.com

Araceli lópez-Guillén García

Correo electrónico: araceli.lgg@gmail.com

Resumen

El número de supervivientes al cáncer con capacidad de trabajar va en aumento gracias a los avances diagnósticos y terapéuticos, pero la reincorporación al trabajo del trabajador que ha padecido cáncer se produce tras un largo periodo de incapacidad laboral y tras haber sufrido un tratamiento agresivo que hacen que el retorno se realice con una aptitud sobrevenida. Dicha aptitud es entendida como la condición del trabajador que tras un periodo de incapacidad en que perdió capacidades, se recuperaron al alta (no incapacidad, alta médica de la baja), pero se reincorpora con una nueva situación de salud (capacidades) y adquiriendo el trabajador y el trabajo nuevos riesgos para su salud y nuevos riesgos frente al trabajo. Se realiza estudio de las bajas por cáncer que duraron más de 365 días, y se realiza un seguimiento de las recaídas que existieron en los seis meses siguientes a la reincorporación. Y se realizan propuestas para garantizar un retorno saludable y eficaz.

Material y método: Con el fin de buscar los artículos sobre el retorno al trabajo tras cáncer, las barreras que se presentan y las propuestas para facilitar el retorno efectivo, se revisaron hasta mayo de 2019 las siguientes bases de datos bibliográficas: SciELO, PUBMED. Se realizó también un estudio de los procesos de cáncer que mantuvieron baja prolongada que alcanzó los 365 días, y se analizó cuántos finalmente concluyeron en alta médica, cuántos de estos procesos de alta tuvieron recaídas en los seis meses siguientes y porqué, y cuántas de las recaídas concluyeron en incapacidad permanente.

Conclusiones: En estudio efectuado sobre trabajadores con bajas por cáncer que alcanzaron o sobrepasaron los 365 días, se comprueba que el $81 \%$ de los casos se incorpora al trabajo con disfunciones que configuran la aptitud sobrevenida y que son estas disfunciones las que causan en un $75 \%$ las recaídas en incapacidad en los seis meses siguientes, haciendo fracasar el retorno laboral. Las disfunciones más predominantes y de mayor impacto son la astenia/fatiga, los trastornos psicológicos (incluyendo ansiedad, bajo ánimo, síntomas depresivos, deterioro cognitivo tipo déficit de atención, concentración o memoria), las disestesias /parestesias, y las artralgias.

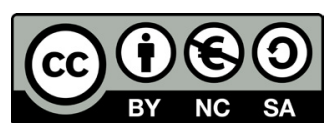

https://creativecommons.org/licenses/by-nc-sa/4.0/ 
La aptitud sobrevenida modifica su capacidad funcional previa y con unos nuevos riesgos para su salud y frente al trabajo. Se precisa un periodo de adaptación obligado para facilitar la recuperación laboral, sin riesgo y de forma saludable y continuada. Es necesario abordar el alta parcial en esta etapa inicial con disminución de las cargas del trabajo, así como un apoyo psicológico al trabajador que padeció cáncer para afrontar la vuelta al trabajo. Son necesarias políticas de apoyo en la empresa que amparen y apoyen la reincorporación y medidas fiscales que las incentiven, así como una mejora de los criterios de valoración de la incapacidad/capacidad laboral y del conocimiento del trabajo mediante el uso de una ficha ocupacional. Debe tenerse en cuenta una consideración preventiva de las decisiones del retorno al trabajo así como una mejora de la comunicación entre agentes implicados en atención sanitaria, gestores de la incapacidad y el mundo del trabajo. Deberá elaborarse un Plan estratégico de protección integral del superviviente del cáncer y conformar un Mapa de Incapacidad Laboral en España para efectuar el análisis de la incapacidad laboral y su impacto económico, social y sanitario, además de permitir evaluar las políticas gestoras.

Med Segur Trab (Internet). 2019;65(255):112-38

Palabras clave: Superviviente de cáncer. Retorno al trabajo. Reinserción laboral. Incapacidad Laboral. Aptitud sobrevenida. Baja laboral. Bajas prolongadas por cáncer. Trabajar después del cáncer. Salud Ocupacional.

\section{Abstract}

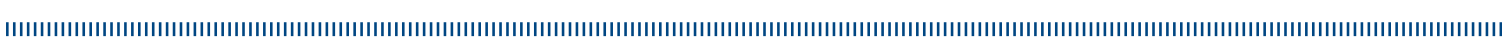

Thanks to the diagnostic and therapeutic advances, the number of cancer survivors able to work is increasing. Nevertheless, the return to work of the worker who has suffered cancer takes place after a long term work incapacity and after having undergone an aggressive treatment causing the return to be made in sudden circumstances. These are understood as the condition of the worker who after a disability period in which he lost capabilities, he received the medical discharge (not disability, medical discharge of the loss), returning to the job in a new health situation (capacities) and facing the worker and the work new risks for his health and new risks at work. A study of more than 365 days sick leave due to cancer was made as well as a six-months-follow-up of the relapses after the returning to work. Proposals are made to ensure a healthy and effective return.

Material and method: In order to search not only the articles about the return to work after cancer but also the barriers that may arise and the proposals in order to facilitate an effective return, the following bibliographic databases up to May 2019 were revised: SciELO, PUBMED. A study of cancer processes that kept prolonged sick leave within a 365-day period was carried out, analyzing how many of them did eventually end in medical discharge, how many of these processes had relapsed in the following six months and why had it taken place, and how many of the relapses ended in permanent disability.

Conclusions: In the study carried out on workers with cancer sick leaves that reached or exceeded 365 days, it has been verified that $81 \%$ of its cases have been incorporated to work with dysfunctions configuring such sudden circumstances. These dysfunctions are precisely the cause of $75 \%$ of the disability relapses in the following six months, causing a failed attempt to return to work. Asthenia / fatigue, psychological disorders (including anxiety, low mood, depressive symptoms, cognitive impairment type attention deficit, concentration or memory), dysesthesias / paresthesias, and arthralgias are the most predominant and most impacting dysfunctions. Supervised aptitude modifies its previous functional capacity undergoing new risks for his health and his work. The following issues should be taken into account: A compulsory adaptation period to facilitate the labor recovery with no risk factors and in a healthy and continuous way; to address the partial discharge in this initial stage reducing the workloads, as well as a psychological support for those cancer workers in order to face the return to work; to support policies in the company protecting and supporting the reincorporation as well as to establish fiscal measures that incentive them; to improve the disability assessment criteria / ability to work, as well as the knowledge of work by using occupational worksheets; to take as well into consideration those preventive returning-to-work decisions; to consider the improvement of the communication between the agents involved in the health care, managers of disability and of the world of work; to prepare a strategic plan for the comprehensive protection of the cancer survivor; to draw up an Occupational Disability Map in Spain in order to carry out the analysis of work incapacity and its economic, social and health impact, as well as to evaluate the management policies.

Med Segur Trab (Internet). 2019;65(255):112-38

Keywords: Cancer survivor. Return to work. Labor reinsertion. Laboral incapacity. Supervening aptitude. Sick leave. Prolonged sick leave due to cancer. Work after cancer. Occupational health. 


\section{INTRODUCCIÓN',2}

En España en 2017 se dieron 90.641 procesos de Incapacidad Temporal por cáncer, el 55\% de los cuales pasaron a Incapacidad Permanente, los 40.700 restantes, el 45\% de los casos se consideró alta del proceso de Incapacidad Temporal o no declaración de grado de Incapacidad Permanente. La prevalencia estimada de supervivientes al cáncer a los cinco años en población trabadora es de 237.200, 106.700 de los cuales supuestamente no les fue considerada la incapacidad permanente. No obstante, las cifras referidas el retorno laboral, efectivo y duradero más allá de los 5 años, parecen ser sensiblemente inferiores; derivado de múltiples circunstancias, bien por recidiva tumoral, o por no poder continuar trabajando con las secuelas del cáncer, o por renuncia personal del trabajador a continuar trabajando o porque finalmente fueron despedidos. En torno al 30\% de los supervienes al cáncer con una primera declaración de alta y retorno al trabajo no permanecerán trabajando más allá de los 5 años del diagnóstico. En el $81 \%$ de los casos de alta médica el retorno no es por curación sino por mejoría funcional con restitución de sus capacidades perdidas que permite trabajar, pero con una "aptitud sobrevenida" derivada de la propia enfermedad, la exposición a tratamientos agresivos durante largo tiempo, y/o las secuelas del propio tratamiento, que hacen que el trabajador haya adquirido nuevos riesgos para su salud y que el trabajo le suponga nuevos riesgos para su salud, por lo que esta aptitud sobrevenida le supone un sobreriesgo añadido.

Riesgo para su salud laboral derivado de la "aptitud sobrevenida" que es preciso contemplar y aminorar procurando políticas de retorno al trabajo multidisciplinarias que faciliten un retorno laboral eficaz y duradero en el tiempo. El trabajador superviviente al cáncer tiene un elevado riesgo añadido de exclusión laboral y social.

Junto al concepto de aptitud sobrevenida, y en qué circunstancias se presenta, acompañamos estudio realizado en trabajadores con cáncer que alcanzaron o sobrepasaron los 365 días y seguimiento de las recaídas, estableciendo conclusiones y finalmente propuestas para un retorno laboral estable de los supervivientes al cáncer, procurando que quién ha sobrevivido al cáncer sobreviva como trabajador.

La aptitud sobrevenida del superviviente del cáncer al retorno al trabajo tras incapacidad laboral prolongada, deriva de la situación que se sucede tras el alta médica de la baja o la no declaración de incapacidad permanente al agotar esta, así que describiremos como puede sucederse el alta, que pone fin a la incapacidad temporal previa.

\section{El retorno al trabajo tras incapacidad laboral por cáncer}

El retorno al trabajo se sucede en incapacidad temporal (IT):

- si el paciente en situación de baja (IT) solicita el alta médica,

- si es decisión del médico que extendió la baja e hizo el seguimiento

- si el alta se considera tras control por entidad competente Inspección Médica INSS o Inspección Médica Servicio Público de Salud

También cabe el retorno al trabajo tras incapacidad permanente revisada por el INSS, y dejada sin efectos o aminorada en grado.

En realidad, de cualquier forma, la incapacidad temporal (IT) supone, que dejamos de ser aptos, frente al alta médica laboral tras IT que supone volvemos a ser aptos. En incapacidad temporal lo que se valora es la incapacidad para el estricto puesto u ocupación y tareas que estaba desempeñando, frente al concepto más amplio de la valoración de la incapacidad permanente que tiene en cuenta la profesión o grupo profesional $u$ ocupaciones afines de referencia incapacitante.

El largo camino de la incapacidad temporal, entre la baja y el alta se sucede en el trascurso de una situación "puente inestable" entre la no aptitud que supone el inicio de la incapacidad y su mantenimiento y la consideración de apto o capacitado tras la conclusión de la incapacidad, en ocasiones un escenario plagado de incertidumbres. 
En los procesos que agotan los 365 días de IT es el INSS a través del Equipo de Valoración de la Incapacidad (EVI órgano colegiado valorador) quién debe de decidir el Alta, la Prórroga de la IT o la declaración de Incapacidad Permanente (IP). Los procesos más frecuentes en IT que duran 1 año o se prolongan más allá del año son: los cuadros Lumbares, los Trastornos Ansiedad, y el Cáncer (destacando el cáncer de mama por si solo), como procesos más habituales.

Se entiende que la indicación de alta y el retorno al trabajo no es posible en los supuestos de cáncer considerados como enfermedad profesional, así como los de origen ocupacional, por riesgo específico constatado con presencia de agente causal del cáncer padecido en el trabajo que desempeñaba.

\section{CONCEPTO DE APTITUD SOBREVENIDA EN EL TRABAJADOR SUPERVIVIENTE AL CÁNCER, QUE RETORNA AL TRABAJO}

La Aptitud Sobrevenida es la condición del trabajador que tras un periodo de incapacidad en que perdió capacidades, se recuperaron al alta (no incapacidad, alta médica de la baja), pero se reincorpora al trabajo con una nueva situación de salud (capacidades) sin restitutio ad integrum, adquiriendo el trabajador y el trabajo nuevos riesgos para su salud.

La aptitud sobrevenida deriva de secuelas disfuncionales que permanecen al alta médica de una baja prolongada, y que presuntamente no condicionan la incapacidad permanente, ni justifican continuar en incapacidad temporal, las más habituales en estar presentes suelen ser: la fatiga/astenia, los trastornos psicológicos/ fragilidad psicológica, los trastornos sensitivos disestesias/parestesias distales, las artralgias, los trastornos de memoria, atención, concentración, el dolor, las disfunciones de órgano y el linfedema. A estos podríamos añadir otros como los trastornos de la piel, trastornos vasculares, trastornos del sueño (Fig. 1).

Figura 1. Aptitud Sobrevenida. Disfunciones. Alta y Retorno laboral.

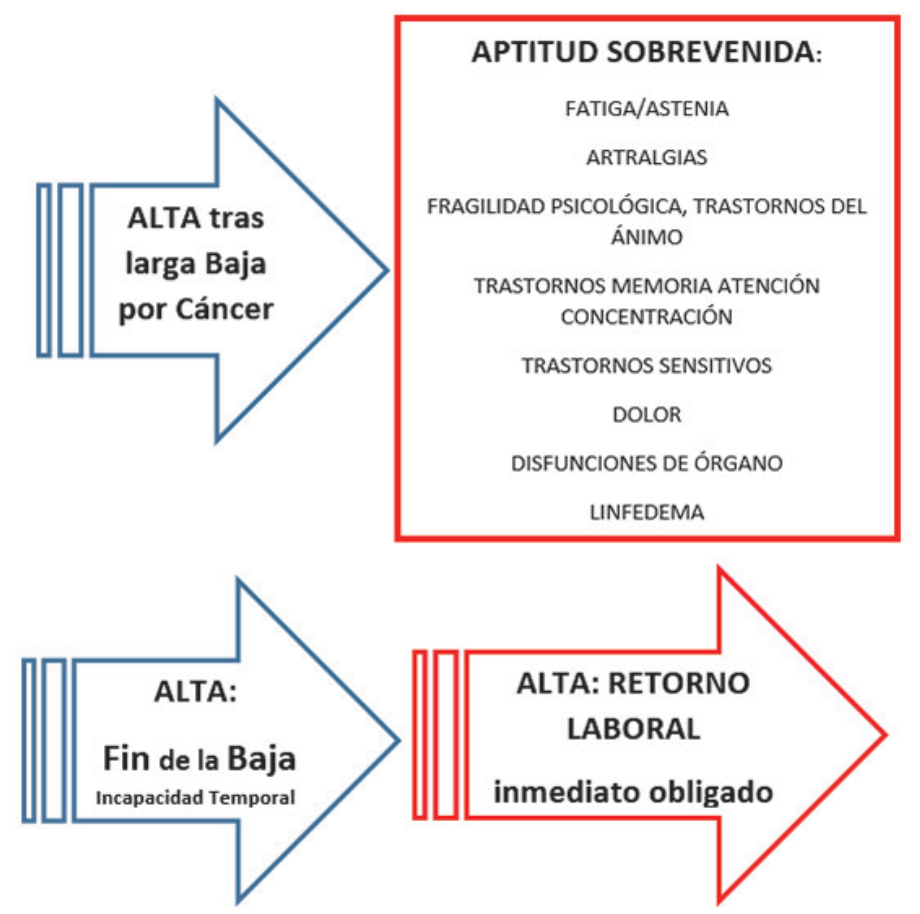

Esta Aptitud sobrevenida, sin embargo, tiene un carácter en muchos casos temporal o transitorio, pues las capacidades restantes, presentes a la declaración de alta 
se entienden son de buen pronóstico evolutivo y no incapacitantes permanentes. En cualquier caso, un periodo de adaptación al inicio de la reincorporación laboral facilitará a largo plazo el desempeño laboral efectivo y saludable por evolución favorable o por mecanismos de adecuación o confrontación funcional.

\section{Aptitud sobrevenida frente a Ineptitud sobrevenida}

El despido objetivo por ineptitud sobrevenida viene regulado legalmente en el Artículo 52. A) del Estatuto de los Trabajadores. La ley prevé la ineptitud sobrevenida como una posible causa de despido objetivo. Por ineptitud, la ley se refiere a la ausencia en la persona del trabajador de las condiciones necesarias para desempeñar su trabajo.

La Aptitud Sobrevenida, supone que, frente a la Ineptitud Sobrevenida, que conlleva al trabajador que, al perder salud, pierda el trabajo, una adecuada valoración de la Aptitud Sobrevenida para que, al recuperar la salud, aunque sea en parte, recupere el trabajo; no obstante, la Aptitud Sobrevenida, sin prevención, sin adaptación llevará a bajo rendimiento, al presentismo del trabajador y puede conllevar el despido en aplicación de la Ineptitud Sobrevenida.

\section{Cuándo sucede la "Aptitud Sobrevenida"}

La aptitud sobrevenida es la nueva condición en que la queda el trabajador, referente a su aptitud, cuando en relación con procesos largos de baja o tras graves dolencias con incapacidad médica larga se plantea el retorno al trabajo, su reintegración al mercado laboral, condicionado por la declaración de alta médica o no declaración de incapacidad permanente, por suponer ha recuperado su capacidad laboral, en contraposición al término de ineptitud sobrevenida término excluyente por el que las pérdidas de las capacidades del trabajador y sus ausencias por incapacidad temporal pueden llevarle al despido. La ineptitud sobrevenida en otras ocasiones deriva del reconocimiento de no apto tras alta por curación o mejoría o tras "retirada" de incapacidad permanente revisada entendiendo ha recuperado su capacidad funcional.

Esta situación de "aptitud sobrevenida" sobreviene cuando se ha puesto fin a la incapacidad laboral pero derivado de la enfermedad, de su larga evolución, de sus secuelas, o por las secuelas derivadas del tratamiento seguido o de la obligada servidumbre terapéutica que mantuvo, o de la afectación sistémica padecida, aun determinando el alta médica o la no declaración de incapacidad permanente que pone fin a la situación de incapacidad laboral, estas circunstancias referidas le confieren al trabajador un riesgo nuevo para su salud y un nuevo riesgo contraído por el trabajador para el trabajo (merma de sus aptitudes) o nuevo riesgo contraído por el trabajador con el trabajo (a los riesgos específicos del trabajo, el trabajar ahora con esas aptitudes mermadas puede dañar su salud) (Fig. 2, Fig. 3).

Figura 2. Aptitud sobrevenida, paso de la incapacidad a la no incapacidad por alta médica "por curación o mejoría que permita al trabajador realizar su trabajo habitual".

\section{APTITUD SOBREVENIDA}

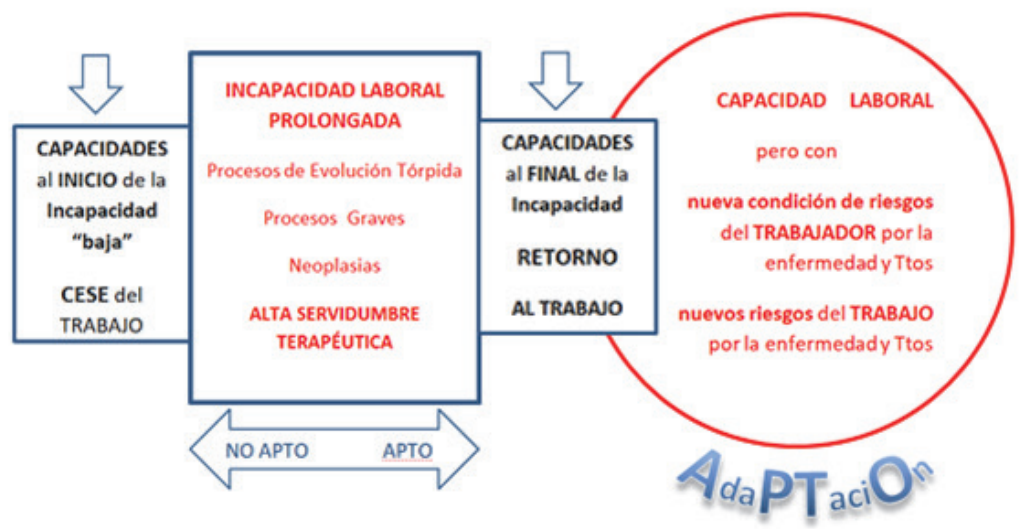

Aptitud sobrevenida tras incapacidad laboral prolongada por cáncer José Manuel Vicente Pardo, Araceli López-Guillén García 
Figura 3. Paso de la incapacidad a la capacidad laboral con aptitud sobrevenida. Ámbito de protección sucesivo.

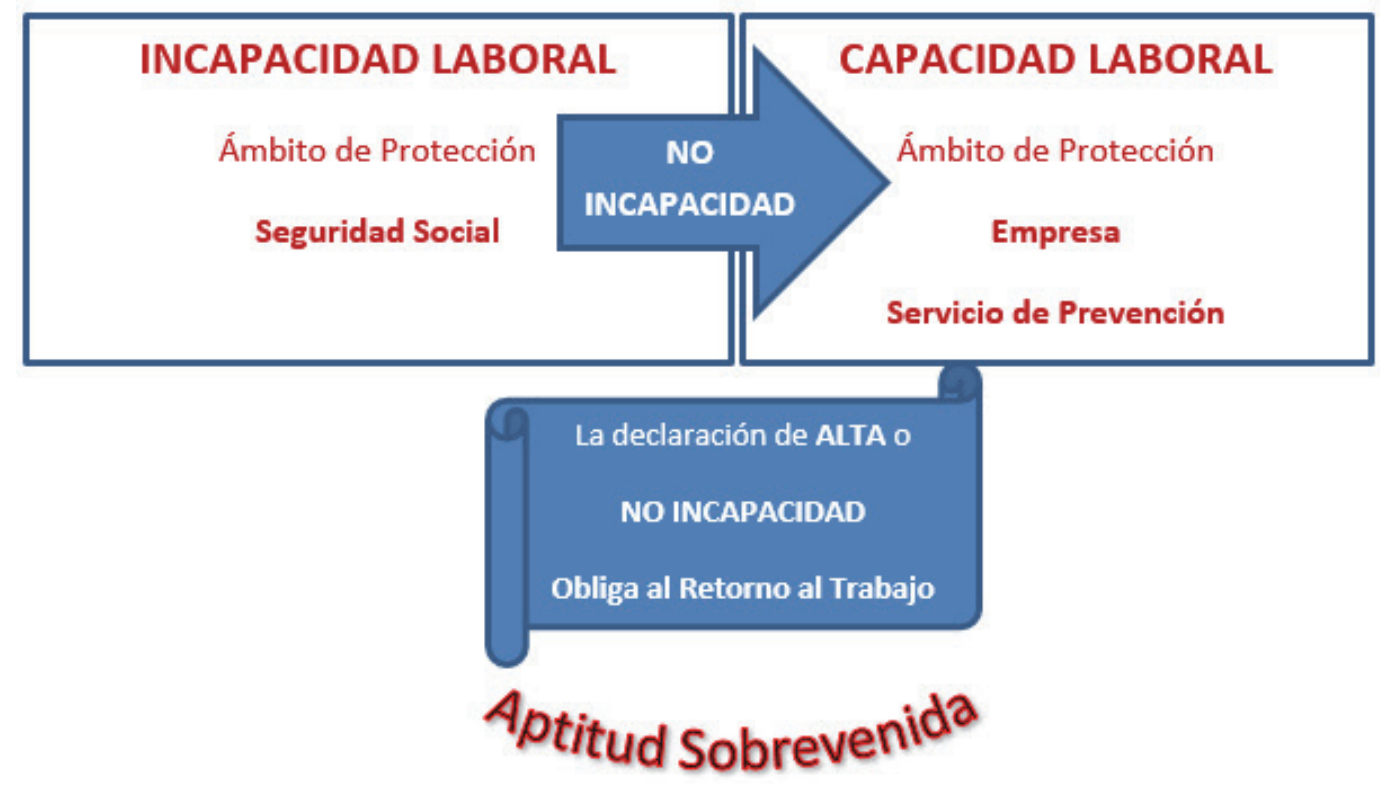

El alta médica o la no declaración de incapacidad al agotar el plazo máximo obligan al inmediato retorno al trabajo. Pasando sin solución de continuidad de la consideración de alta o capacidad o curación o mejoría suficiente que permite trabajar (realizar su trabajo habitual). Tras el alta médica que pone fin a la larga incapacidad laboral el trabajador ha adquirido nuevos riesgos para su salud y el trabajo le supone nuevos riesgos para su salud. Es decir, la aptitud sobrevenida supone un sobreriesgo añadido.

\section{El alta médica y el retorno laboral, la norma aplicable}

El alta médica puede ser por curación o mejoría que permita al trabajador realizar su trabajo habitual. No existiendo definición del alta médica en la Ley General de Seguridad Social (LGSS 2015), salvo las consideraciones de suspensión o extinción del subsidio, se entiende es porque no se cumplen los requisitos establecidos en el artículo 169 de la LGSS, que define la situación de incapacidad temporal como las situaciones de enfermedad o accidente mientras el trabajador reciba asistencia sanitaria de la Seguridad Social y esté impedido para el trabajo, con una duración máxima de trescientos sesenta y cinco días, prorrogables por otros ciento ochenta días cuando se presuma que durante ellos puede el trabajador ser dado de alta médica por curación.

Además de estas apreciaciones médico laborales tras el alta médica de un proceso de larga duración como el que se da en los pacientes con cáncer tenemos que tener en cuenta la desaparición de la situación jurídica de protección frente a la manifestación de la enfermedad del trabajador que confiere el artículo 45 del Estatuto de los Trabajadores, y que en la incapacidad temporal asegura el mantenimiento del vínculo contractual durante el periodo en que el trabajador no puede prestar servicio por estar enfermo, artículo que añade amparo al derecho a la protección de la salud articulo 43.1 Constitución Española principio rector de la política social y económica.

El alta médica o la no declaración de grado de incapacidad permanente de un proceso de larga duración de la incapacidad temporal por cáncer pone fin de la prestación económica de la incapacidad en materia de seguridad social. Extinción IT artículo 174 LGSS.

La reincorporación al trabajo tras larga incapacidad laboral por cáncer supone la necesaria evaluación especificada en el Artículo 37 apartado b $2^{\circ}$, del Reglamento de 
los Servicios de Prevención Real Decreto 39/1997, que establece una evaluación de la salud de los trabajadores que reanuden el trabajo tras una ausencia prolongada por motivos de salud.

Así mismo y acorde con lo estipulado en el artículo 22 de la Ley 31/1995 de Prevención de Riesgos Laborales se deberá proceder a la vigilancia de la salud para evaluar los efectos de las condiciones de trabajo sobre la salud de los trabajadores o para verificar si el estado de salud del trabajador puede constituir un peligro para el mismo, en relación con la protección de riesgos específicos y actividades de especial peligrosidad.

Y, sobre todo, la supuesta condición de "trabajador sensible" a la que alude el artículo 25 de la Ley de Prevención de Riesgos Laborales, que refiere que el empresario garantizará de manera específica la protección de los trabajadores que, por sus propias características sean especialmente sensibles a los riesgos derivados del trabajo, y que a tal fin, adoptará las medidas preventivas y de protección necesarias, de forma que los trabajadores no serán empleados en aquellos puestos de trabajo en los que, a causa de sus características pueda ponerse en situación de peligro de su salud en general, o cuando se encuentren manifiestamente en estados o situaciones transitorias que no respondan a las exigencias psicofísicas de los respectivos puestos de trabajo.

\section{Alta o no incapacidad, Aptitud sobrevenida y riesgos contraídos}

Hablamos de aptitud sobrevenida desde la perspectiva de inclusión, o de favorecer el retorno al trabajo, pues si se consiguió una curación de un proceso que ha mantenido una prolongada incapacidad médica laboral o se consiguió una mejoría que faculta este retorno a un trabajo para el que se han recuperado las capacidades funcionales requeridas, se debe proceder sin que ello suponga un riesgo para su salud, y permita además seguir con las pautas terapéuticas, si estuvieran indicadas.

La aptitud sobrevenida supone un sobreriesgo a los riesgos para su salud presentes en el trabajador que el trabajador tenía previamente al contraer la enfermedad.

Tras el alta médica o la no declaración de incapacitado tras larga incapacidad se constituye la aptitud sobrevenida, fruto de la larga estancia como incapacitado, el alejamiento del trabajo y las secuelas del cáncer, y/o los tratamientos, el trabajador al alta por curación o mejoría suficiente adquiere una nueva condición de apto para el retorno al trabajo, si bien el cáncer ha supuesto un antes y un después.

Lo que importa al valorar la carga de secuelas que conforman la "aptitud sobrevenida" es su carácter consecuente al determinar el riesgo a la vuelta al trabajo y al ser consecuencia de la recaída en incapacidad laboral tras el inicial retorno (supuestos de recaídas no derivadas de recidiva tumoral) o la renuncia, la dimisión interior del trabajador al trabajo al considerar este dañino para su salud y sentirse incapaz de poder desarrollarlo con eficacia.

El concepto de Aptitud Sobrevenida guarda relación con la valoración presumible e implícita de una consideración de Aptitud que va a producirse tras el alta médica o la no declaración de incapacidad, concibe una nueva situación de riesgos por la enfermedad para el trabajo y por el trabajo para la enfermedad padecida.

La aptitud sobrevenida supone ya no existen las limitaciones funcionales que dieron lugar al mantenimiento de la baja o la incapacidad laboral durante largo tiempo, o también que la funcionalidad restante considerada en su favorable evolución permita el desarrollo del trabajo, y en consonancia vaya a producirse una presumible valoración de apto, no obstante lo cual el trabajador retorna al trabajo en una nueva situación aptitudinal, que merece ser atendida tanto para la estimación del alta como en la adaptación necesaria.

La aptitud sobrevenida tras alta de largo proceso de incapacidad temporal (IT) supone se está capacitado (no se está ya incapacitado) pero con un nuevo riesgo contraído.

En realidad, el concepto de aptitud sobrevenida tras larga incapacidad es aplicable no solo al cáncer sino a enfermedades graves con riesgo vital y con larga incapacidad, 
pero si hay una situación definitoria de la aptitud sobrevenida, por excelencia esta se da en los supervivientes al cáncer, por las disfunciones o limitaciones funcionales específicas que presenta, derivadas del propio cáncer o de los tratamientos a los que ha estado sometido.

\section{Nuevos riesgos del superviviente de cáncer al retorno laboral}

Las secuelas o mermas tras el cáncer, aun no constituyendo una incapacidad laboral si constituyen nuevos riesgos. Sólo el $20 \%$ de los pacientes con cáncer son dados de alta por curación y sin limitación funcional alguna (normofunción y ausencia de sintomatología). El $80 \%$ de los pacientes con cáncer son dados de alta con secuelas de baja intensidad o leves, es decir, por mejoría que permite al trabajador realizar su trabajo habitual. Pero así las cosas el trabajador ha adquirido un mayor riesgo para su salud y el trabajo supondrá mayor riesgo que el que suponía antes de que el trabajador sufriera el cáncer.

El tipo de secuelas o mermas funcionales más habituales tras el cáncer, son: la fragilidad psicológica, la astenia o fatiga, las artralgias, las disestesias o parestesias, disfunción orgánica o miembro contiguo, dolor en región peritumoral, linfedema o edema y situación anatómica pendiente de cirugía.

La fragilidad psicológica (alteraciones psicológicas: trastorno del ánimo, de las emociones, síndrome depresivo, alteraciones del sueño), y el chemo brain (trastornos de la memoria, la atención, la concentración y la capacidad para realizar diversas tareas mentales), determinan un mayor riesgo frente a tareas con demandas exigentes de apremio o toma rápida de decisiones o tareas de alta responsabilidad, implican menor capacidad de respuesta o solución de situaciones con requerimientos estresantes, que precisen capacidad de ejecución o resolución inmediata y continuada, manejo de vehículos o maquinaria peligrosa.

La astenia o fatiga, las artralgias, o el dolor aún de bajo grado, así como las parestesias o disestesias (síndrome de mano-pie: déficit de sensibilidad en manos y/o pies) comportan un mayor riesgo para realizar esfuerzos físicos, posturas forzadas, manipulación manual de cargas, movimientos repetidos continuados, destreza manual, o manejo de maquinaria peligrosa.

El linfedema o edema se entiende de bajo grado, va a comportar un mayor riesgo para manejo de pesos, cercanía a fuentes de calor, porteo de pesos, acciones con brazos en alto continuadas.

Las disfunciones de órgano, entiéndase si fueron no incapacitantes serán leves, pero en general, comportaran una merma para actividades de esfuerzo muy exigente, o en otros casos presión sobre órgano afecto, o cuando existe disfunción de miembro contiguo (brazo en caso de cáncer de mama) ocasionaran merma para actividades de esfuerzo, o dinámicas exigentes para el mismo.

Por otra parte, puede haber contraído un mayor riesgo vascular, casos de cardiotoxicidad evidenciada durante el tratamiento, o ser cautelosos para actividades de corte físico muy exigentes de haber seguido tratamiento con antraciclinas, trastuzumab, así como otras quimioterapias como la ciclofosfamida, la mitomicina, el imatinib, el 5 fluorouracilo, la capecitabine, el taxano o el bevacizumab, tienen también riesgo de cardiotoxicidad.

\section{Alta o No Incapacidad y Retorno Laboral, elementos que la configuran}

\section{El cáncer, el trabajador y el trabajo}

El retorno dependerá en cuanto al cáncer: del tipo de cáncer, del subtipo de cáncer, su estadio, su pronóstico, sus consecuencias limitantes, la evolución y la repuesta al tratamiento; en cuanto al trabajador: de la percepción del trabajador, de la obligada aceptación decisoria del médico o entidad que considera está de alta (médica); y en lo 
referente al trabajo: de la profesión, puesto, tareas, formación, riesgos y condiciones especiales (Fig. 4).

Figura 4. Factores circundantes al retorno al trabajo.

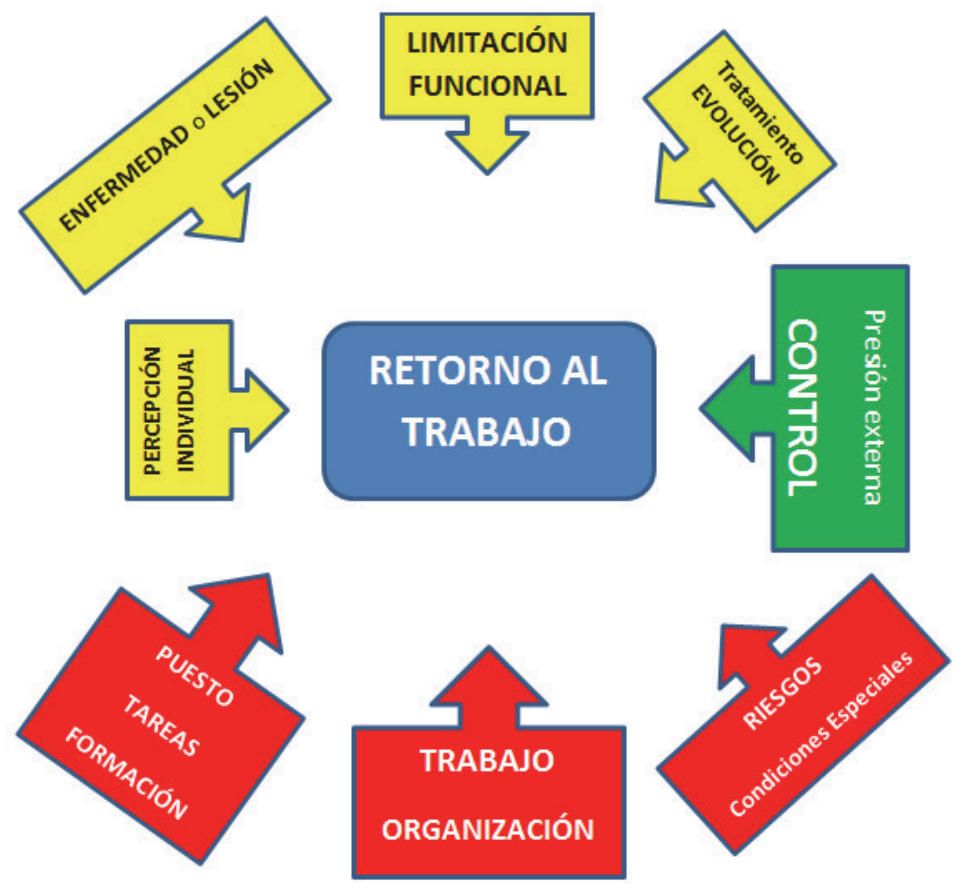

\section{La APTITUD SOBREVENIDA y su valor PREVENTIVO de la salud laboral}

En la valoración de los trabajadores dados de alta o considerados como capacitados por no declaración de la incapacidad laboral tras incapacidad médica laboral prolongada no sólo hay que tener en cuenta lo "prestacional", en esencia situación conforme con la definición de la incapacidad temporal o permanente, sino ir más allá, y analizar lo "preventivo", teniendo en cuenta las consecuencias del alta médica o la no incapacidad reconocida, pues tras esta larga incapacidad:

- El trabajador ha contraído un mayor riesgo tras la enfermedad, por las limitaciones funcionales residuales, por las secuelas del tratamiento al que fue o sigue sometido, y por la consideración preventiva que proceda para evitar recidiva, la recaída en incapacidad o la repercusión en su salud.

- Las características del trabajador tras larga enfermedad incapacitante pueden suponer en algunos casos un mayor riesgo en el trabajo por algunas de las secuelas o residuales de la enfermedad o de su tratamiento aun estando supuestamente capacitado.

- Las características del trabajo pueden suponer en algunos casos un mayor riesgo de enfermedad o lesiones y un mayor riesgo de empeoramiento del estado de salud o no hacer posible el seguimiento terapéutico al trabajador retornado.

El concepto de APTITUD SOBREVENIDA guarda relación con la valoración presumible e implícita de una consideración de APTITUD que va a producirse tras el alta médica o la no declaración de incapacidad, concibe una nueva situación de riesgos por la enfermedad para el trabajo y por el trabajo para la enfermedad padecida.

La aptitud sobrevenida justificaría los cambios normativos en Incapacidad Temporal que permitieran las Incorporaciones o Altas Parciales, esta nueva figura dela Alta podría completar la adaptación del trabajo al trabajador, los "aptos con restricciones". El alta 
parcial permitiría una incorporación gradual al trabajo; evitando el salto brusco de pasar de no estar capacitado a estarlo al día siguiente de la declaración de alta.

Determinados colectivos como los autónomos, los trabajadores con trabajos "fragmentados" o pluriempleados (cotizaciones en régimen general) o con pluriactividad (cotización en dos regímenes de seguridad diferente), trabajadores en empresas pequeñas o determinados cometidos específicos, pueden hacer en la práctica imposible el apto con restricciones por ello el alta es pasar de cero a cien en la capacidad productiva laboral sin amparo lo que puede llevar a fracasar la reincorporación al trabajo.

\section{El CÁNCER y la APTITUD SOBREVENIDA tras el ALTA MÉDICA LABORAL - la No declaración de Incapacidad Permanente}

La consideración de la APTITUD SOBREVENIDA tras el CÁNCER merece una consideración especial. En el SUPERVIVIENTE al cáncer encontramos que supuso una vivencia de riesgo vital, padeció una severa afectación funcional durante tiempo prolongado, sufrió una elevada intensidad terapéutica hasta la mejoría o curación y las dolencias y limitaciones residuales tras el tratamiento acostumbran a permanecer durante tiempo, aunque fuera de forma larvada o de leve intensidad.

En el cáncer se da una vivencia de riesgo vital mantenida desde el conocimiento del diagnóstico hasta la conclusión del mismo e incluso aunque haya terminado el tratamiento por el riesgo y miedo a la recaída, esta vivencia de estar en situación de riesgo vital determina la aparición del estrés, la ansiedad y/o el abatimiento emocional que mina la resistencia psíquica, merma las capacidades psíquicas, la actitud y la motivación.

En el cáncer es habitual el seguimiento de tratamientos prolongados, intensos y continuados a lo largo de todo el proceso, incluso más allá de la curación o remisión, es decir, con una gran servidumbre terapéutica. A ello añadir la diferente consideración entre alta médica laboral y el alta sanitaria en el momento del retorno laboral, en el cáncer puede que el alta sanitaria no se produzca hasta meses después del alta médica laboral. Además, en el cáncer a diferencia de otros procesos la remisión completa o la ausencia de tumor (enfermedad) no son suficientes para la consideración inmediata del alta médica laboral. El desempeño del trabajo debe ser compatible con aquellos tratamientos que fueran precisos mantener con continuidad.

En otros procesos de incapacidad larga los tratamientos son agresivos al inicio o puntuales en momentos evolutivos, pero no tiene este carácter tan común de intensidad y agresividad continuada que conlleva el tratamiento del cáncer. El factor de riesgo vital puede ser común a otros graves procesos, pero en esos casos suele desaparecer tras la respuesta favorable al episodio agudo, en el cáncer ese sentimiento de estar en riesgo vital es mucho más largo y en algunos casos incluso supera el momento del cese del tratamiento.

Las residuales en el cáncer, suponiendo casos en los que ha recuperado la funcionalidad perdida, es decir estos supuestos para la consideración de "aptitud sobrevenida tras alta médica" o señalamiento de no incapacidad, pueden presentar signos clínicos y limitaciones de determinación objetiva difícil, aunque esperada y con carácter disfuncional difuso global como son la astenia o fatiga, los trastornos del sueño, los dolores articulares, las parestesias, los trastornos emocionales o el "chemo brain", en español literalmente "quimio-cerebro" (trastornos en la memoria, la atención, la concentración y la capacidad para realizar diversas tareas mentales), que están asociados a la recepción de tratamientos de quimioterapia.

Las características del trabajador tras el cáncer pueden suponer en algunos casos un mayor riesgo en el trabajo por algunas de las secuelas o residuales que el cáncer o su tratamiento dejó en el trabajador superviviente y supuestamente capacitado.

Las características del trabajo pueden suponer en algunos casos un mayor riesgo de enfermedad o lesiones y un mayor riesgo de empeoramiento del estado de salud o no 
hacer posible el seguimiento terapéutico al trabajador retornado tras el cáncer. Recordar que la menor resistencia al esfuerzo, el "chemo brain", las parestesias, el cansancio o el dolor pueden suponer mayor riego de accidentalidad.

Por todo ello se hace imprescindible la evaluación específica y cuidadosa del riesgo al retorno al trabajo tras cáncer, para que aun considerando al trabajador como CAPACITADO laboral a efectos de seguridad social y secundariamente la declaración de APTO por su servicio de prevención, mantengamos las garantías de adaptación del trabajo y como no la indicación de alta o no incapacidad debidamente efectuada y valorada.

La consideración preventiva de estar CAPACITADO (NO INCAPACITADO) o en situación de ALTA tras incapacidad laboral prolongada por cáncer, se hará, suponiendo el trabajador tiene una capacidad laboral restante compatible y capaz para el desempeño laboral que venía desarrollando. Un trabajo que no perjudique su salud resentida y que permita seguir los tratamientos de continuación sin mermar su esperada respuesta terapéutica y el necesario alejamiento de factores de riesgo cancerígeno. Conlleva la implícita valoración, no siempre coincidente ni exenta de litigio, de la consideración de APTITUD. Pues puede darse la controversia de NO INCAPACIDAD, o CONSIDERACIÓN DE ALTA y la declaración de NO APTO, más frecuentemente que en otros procesos de larga incapacidad laboral. Con el riesgo de despido.

La aptitud sobrevenida es una situación límite entre el alta y la obligada incorporación al trabajo con la estimación de aptitud y la adopción de medidas de adaptación del puesto y condiciones de trabajo como consideración de un apto con restricciones temporales; así mismo implica una correcta evaluación de la consideración del alta médica o la no declaración de incapacidad con carácter preventivo soportada en la objetivación de las limitaciones funcionales y el conocimiento de las tareas del trabajo, entendiendo que el alta supone que se tiene capacidad laboral, pues las capacidades del trabajador son compatibles con las capacidades que requiere su trabajo, y porque el estado de salud y de seguir precisando de tratamiento es compatible con el trabajo.

\section{ESTUDIO DE PROCESOS DE CÁNCER CON LARGA INCAPACIDAD TEMPORAL (MÁS DE 365 DÍAS) QUE CAUSARON ALTA MÉDICA}

\section{Objetivo}

Analizar procesos de incapacidad temporal (IT) de larga duración por Cáncer, es decir, que alcanzan o superan los 365 días y finalizan con alta médica laboral. Y de estas altas con retorno al trabajo, cuantos procesos causan recaída en incapacidad temporal en los siguientes 6 meses tras el alta médica y por qué motivo; así como servir de base para establecer propuestas en situaciones de "aptitud sobrevenida" que supongan retornos al trabajo eficaces, lo que es tanto como aminorar las recaídas y posibilitar la continuidad en el trabajo de los supervivientes de cáncer.

\section{Método}

Se registraron procesos con IT que alcanzaran los 365 días, hasta marzo 2018, y a lo largo del semestre previo, para poder hacer seguimiento de las recaídas, incluyendo aquellos procesos que hubieran sido prorrogados hasta los 545 días. Una vez conocidos los casos de cáncer, que fueron 236, se inició el análisis de aquellos que hubieran causado alta médica, que correspondían a 111 casos, y se procedió al estudio de los informes médicos de valoración que la incapacidad laboral que sustentaron la declaración del alta médica laboral, de estos 111 casos de cáncer. Posteriormente se procedió a valorar aquellos con recaída en IT, en el periodo de 6 meses siguientes al alta, considerada la recaída derivada de "mismo proceso", que fueron 22 casos, y se estudiaron los informes médicos de valoración que la incapacidad laboral que admitían esta recaída. Los procesos analizados corresponden a Gipuzkoa. 


\section{Valoración de procesos que superaron los 365 días de baja. Datos}

El estudio (Tabla 1) registró 1794 procesos de Incapacidad Temporal (IT) que alcanzaron o superaron los 365 días, 236 casos, un 13, 15\% eran por cáncer y 1558 casos, el $87 \%$ por el "resto de procesos" (Fig. 5), se hizo seguimiento y análisis de la información médica de todos los procesos de cáncer, así como averiguar y estudiar sus recaídas en incapacidad temporal.

Tabla 1. Procesos de Incapacidad Temporal por Cáncer de más de 365 días. Altas. Recaídas.

\begin{tabular}{c|c|c|c|c|c}
\hline $\begin{array}{c}\text { Procesos totales } \\
\text { con > 365 días } \\
\text { de IT }\end{array}$ & $\begin{array}{c}\text { Procesos } \\
\text { por cáncer } \\
\text { con > 365 días } \\
\text { de IT }\end{array}$ & $\begin{array}{c}\text { Altas por cáncer } \\
\text { de procesos } \\
\text { de > 365 días } \\
\text { de IT }\end{array}$ & $\begin{array}{c}\text { Recaídas de altas } \\
\text { por cáncer } \\
\text { por disfunción }\end{array}$ & $\begin{array}{c}\text { Recaídas de altas } \\
\text { por cáncer } \\
\text { por recidiva } \\
\text { tumoral }\end{array}$ & $\begin{array}{c}\text { Recaídas de } \\
\text { altas por cáncer } \\
\text { disfunción + } \\
\text { recidiva tumoral }\end{array}$ \\
\hline 1794 & 236 & 111 & 18 & 4 & 22 \\
\hline
\end{tabular}

Figura 5. Procesos de Incapacidad Temporal (IT) que alcanzaron o superaron los 365 días.

\section{PROCESOS de IT de > 365 días}

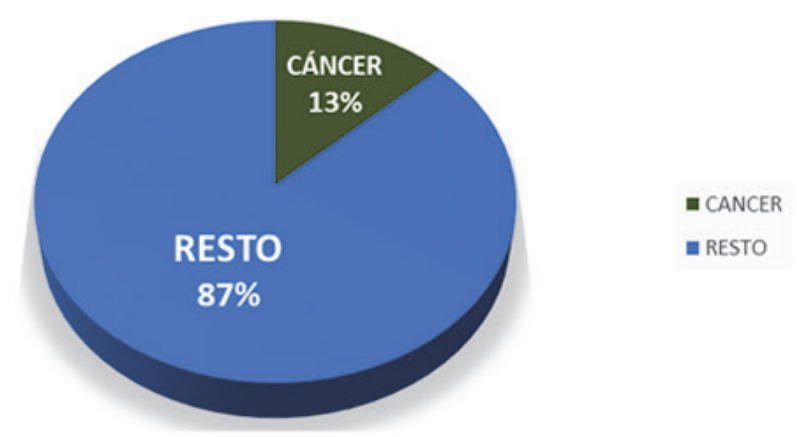

Este dato del 13\% de este estudio en Gipuzkoa, concuerda con los datos a nivel de España, donde el Cáncer es por capítulos diagnósticos la $3^{a}$ causa de las bajas que se prolongan hasta el año (Fig. 6).

Figura 6. Procesos por capítulos diagnósticos que alcanzan los 365 días de baja. Datos INSS.

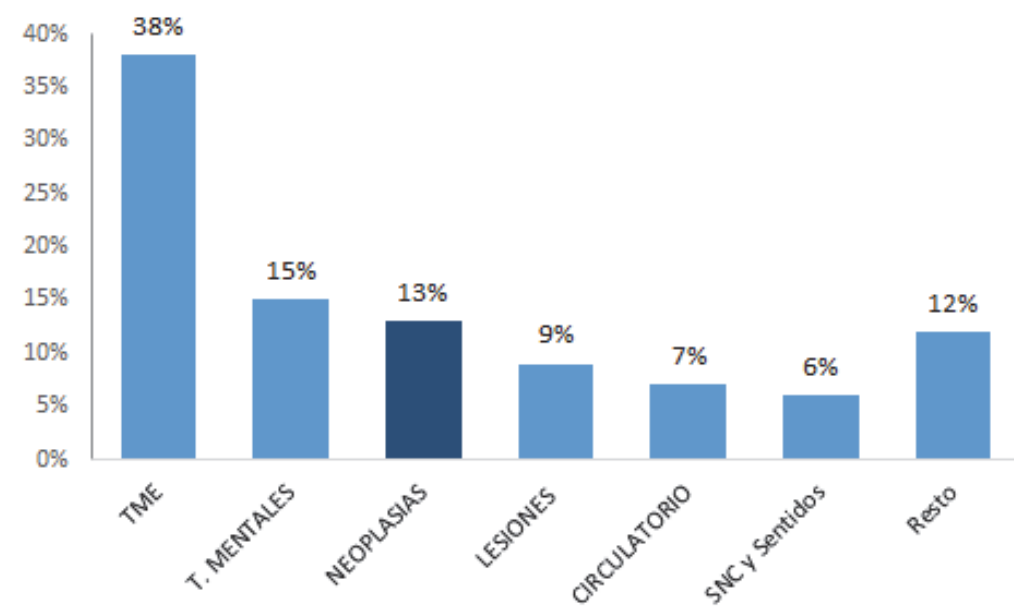

De estos 236 procesos de cáncer con duración de más de 1 año, se consideró el Alta por curación o mejoría funcional suficiente en 111 casos de cáncer, es decir en un 53\%, y se inició valoración de Incapacidad Permanente (IP) en un 47\%, que corresponde a 125 casos con tal estimación de proceso no incapacitante permanente (Fig. 7). 
Figura 7. Procesos de Cáncer con ALTA o INCAPACIDAD PERMANENTE tras más de 1 año de baja.

\section{Procesos de Cáncer con IT de > 365 días ALTA / INCAPACIDAD PERMANENTE}

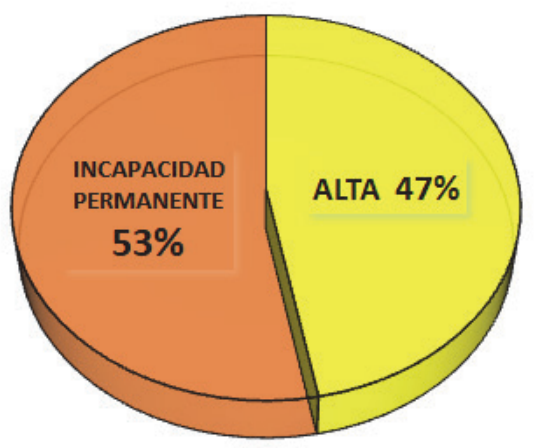

El "alta" pone fin a la prestación económica de incapacidad temporal (IT), y obliga a la reincorporación laboral. Señalar que el "alta" entendida como "alta médica laboral" puede no coincidir con el "alta médica", es decir puede que se considere el alta y que el trabajador continúe con tratamiento y seguimiento médico. El alta puede ser por curación o por mejoría funcional que permite trabajar.

Como el objeto de este estudio es analizar la aptitud sobrevenida tras larga incapacidad por cáncer y en qué medida la no adaptación del puesto de trabajo puede condicionar una recaída del proceso o un no retorno laboral efectivo, se estudiaron los motivos del alta, y la presencia o no de estas variables trastorno psíquico, neurotoxicidad, dolor, disfunción órgano afectado, artralgias, linfedema, astenia.

Se realizó un seguimiento de las 111 altas médicas que pusieron fin a la Incapacidad Temporal tras permanecer en esa situación durante más de un año, y se analizaron las recaídas en los 6 meses siguientes al alta médica laboral y su retorno al trabajo.

\section{ALTAS POR CÁNCER de ITs que superaban los 365 días de duración}

Los 111 procesos de cáncer con alta médica correspondían a los siguientes, tipos de cáncer, grupos etarios, profesiones y con las secuelas no limitantes que se describen a continuación.

En cuanto al tipo de cáncer más frecuente de los que que causaron alta tras más de 365 días en IT, destaca el cáncer de mama (Fig. 8).

Figura 8. Tipo y número de casos de cáncer que causaron alta de ITs de más de 365 días.

\section{Cánceres con Alta tras >365 d IT}

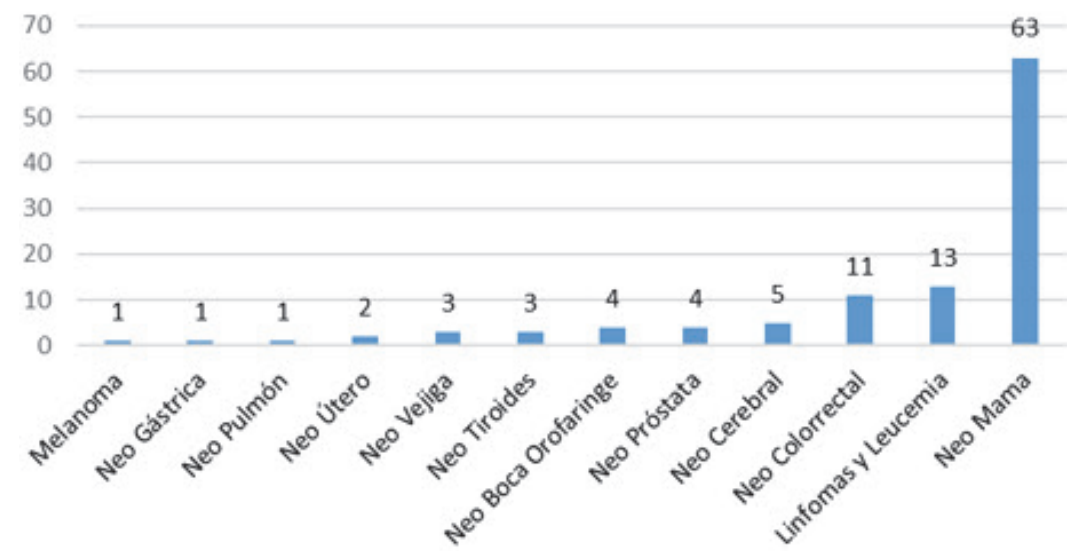


El 57\% de los cánceres con duración de IT de más de 1 año que han sido analizados en este estudio, correspondían al cáncer de mama. El cáncer de mama es en España el primer diagnóstico de procesos de IT que alcanzan la duración de 12 meses (Fig. 9).

Figura 9. Diagnósticos más frecuentes de bajas que alcanzan los 365 días de baja. Datos INSS.

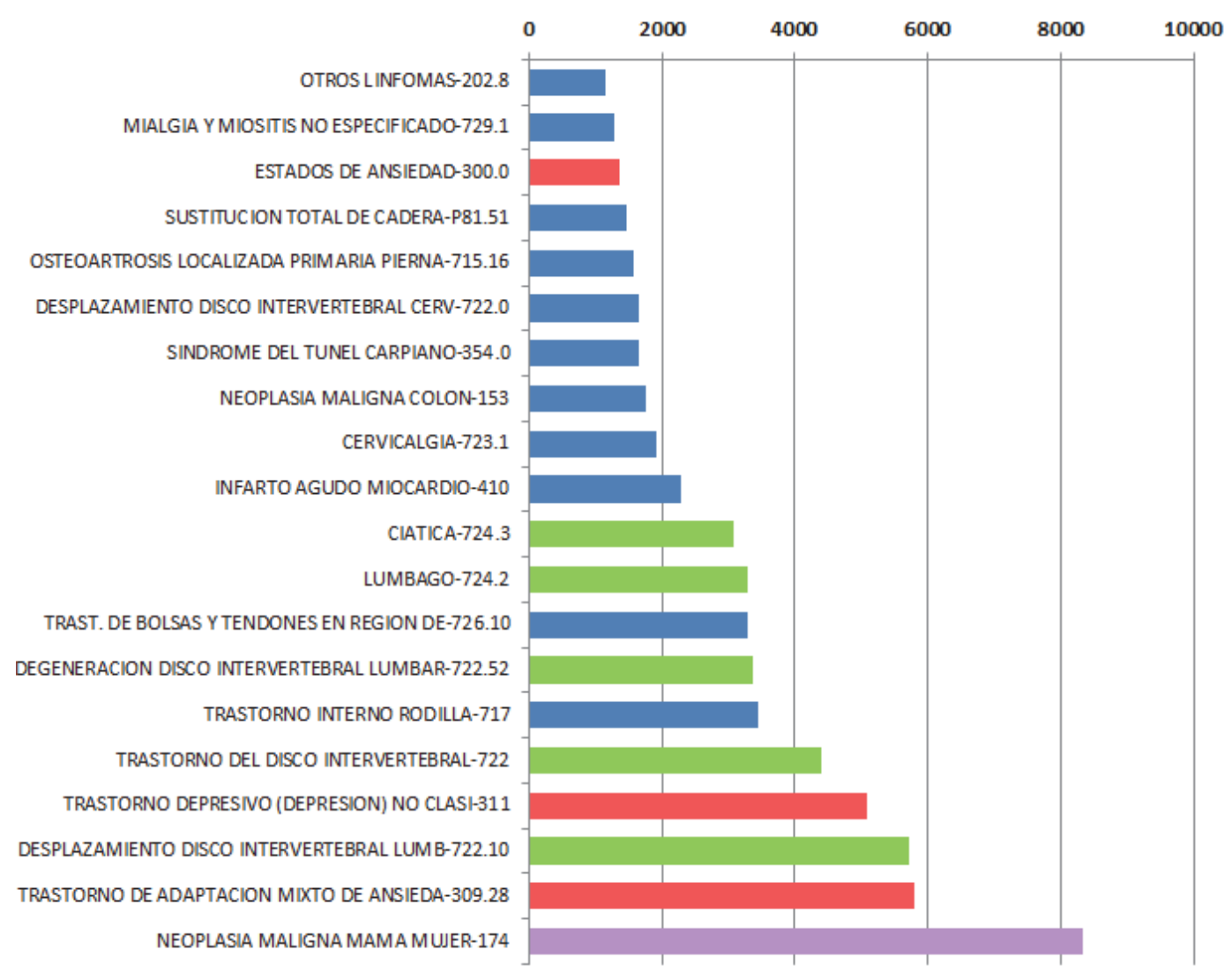

\section{EDAD. Grupos etarios de cánceres que causaron ALTA tras $>365$ días en IT}

El grupo más numeroso de edad fue el correspondiente a pacientes entre los 56 y los 60 años (Fig. 10).

Figura 10. Grupos de edad cáncer con alta tras más de 365 días en IT.

Grupos de edad CÁNCERES con ALTA tras IT > 365 d.

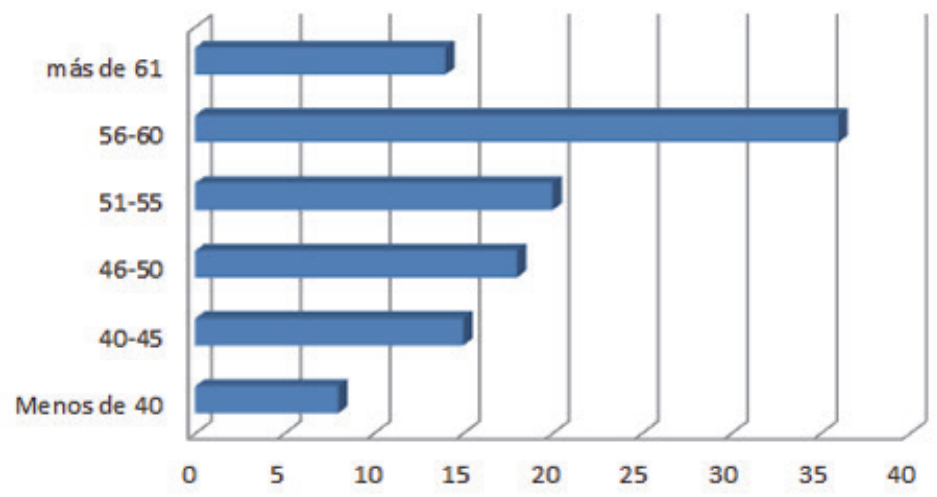

En cuanto a las profesiones se recogen datos en Tabla 2, destacando los que realizaban tareas administrativas. 
Tabla 2. Profesiones de cánceres que causaron alta tras $>365$ días en IT.

\begin{tabular}{l|l}
\hline Tareas administrativas & 25 \\
\hline Dependientes comercio & 10 \\
\hline Profesor & 9 \\
\hline Auxiliar sanitario & 9 \\
\hline Limpieza & 8 \\
\hline Operario, peón & 7 \\
\hline Cuidadores & 5 \\
\hline Conductor & 5 \\
\hline Enfermería & 4 \\
\hline Camarero & 3 \\
\hline Trabajador social & 3 \\
\hline Personal de hotel & 3 \\
\hline Empleado de banca & 3 \\
\hline Empleada de hogar & 2 \\
\hline Almacenero & 2 \\
\hline Agraria & 2 \\
\hline Cartero & 2 \\
\hline Cocinero & 1 \\
\hline Cajero supermercado & 1 \\
\hline Panadero & 1 \\
\hline Montaje & 1 \\
\hline Electricidad & 1 \\
\hline Tapicero & 1 \\
\hline Soldador & 1 \\
\hline Otro personal sanitario & 1 \\
\hline Carrocero & 1 \\
\hline & \\
\hline
\end{tabular}

\section{SIGNOS Y SÍNTOMAS de cánceres que causaron alta tras > 365 días en IT}

De los 111 casos con alta, en 21 casos, el alta médica laboral que puso fin a la incapacidad temporal prolongada (procesos de cáncer con duración de IT de más de 1 año), fue por curación no recogiéndose dolencia ni limitación alguna y señalando la normofunción global.

En 90 casos el alta médica laboral que puso fin a la incapacidad temporal prolongada (procesos de cáncer con duración de IT de más de 1 año), fue por mejoría funcional que permitía trabajar, se analizaron y recogieron estas dolencias citadas en el médico de evaluación de la incapacidad laboral en grado leve o que puestas en relación con su trabajo no eran incapacitantes: Astenia, parestesias y disestesias, trastornos psicológicos, artralgia, disfunción orgánica o miembro contiguo, dolor en región peritumoral, linfedema o edema y situación anatómica pendiente de cirugía (Fig. 11).

Estos 21 casos de cáncer, en los que en el informe médico de evaluación de la incapacidad laboral no registraba ningún trastorno y se reflejaba curación y normofunción completa, se trataba de procesos considerados como Grado Funcional 0, que referiremos a continuación de que se trata, y que se considera para supuestos de cáncer curado, sin necesidad de tratamiento (o tratamiento sin indisposición o disfunción resultante alguna), sin síntomas y capacidad funcional restituida. 
Figura 11. Altas de IT de más de 365 días. Altas con secuelas no incapacitantes, Altas por curación.

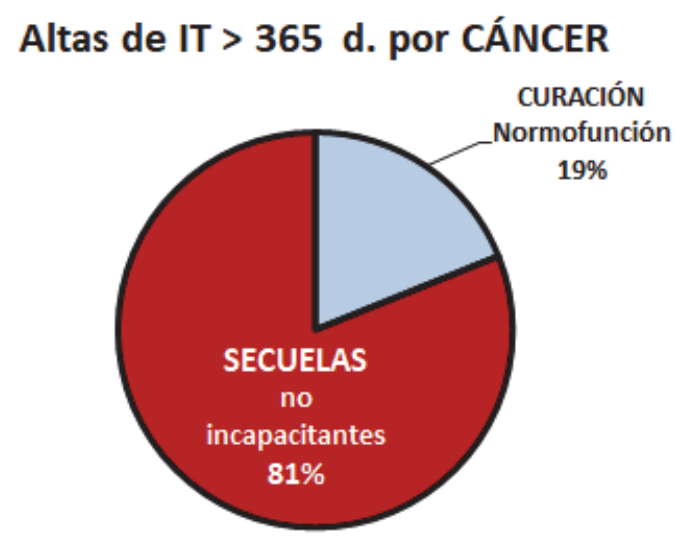

En 90 casos de alta, se entendía se trataba de grado funcional 1, y presentaban uno o varios de los signos y síntomas siguientes, sin condicionar impedimento laboral: Astenia o fatiga, neurotoxicidad (parestesias, disestesias), trastornos psicológicos (incluyendo ansiedad, bajo ánimo, síntomas depresivos, deterioro cognitivo tipo déficit de atención, concentración o memoria), artralgias, disfunción de órgano afecto o miembro contiguo, dolor en región paratumoral, linfedema o edema, o se hallaban pendientes de cirugía de reconstrucción (Fig. 12).

Figura 12. Relación de secuelas presentes al alta por mejoría tras IT de más de 365 días.

\section{Secuelas presentes al Alta tras IT > 365 d}

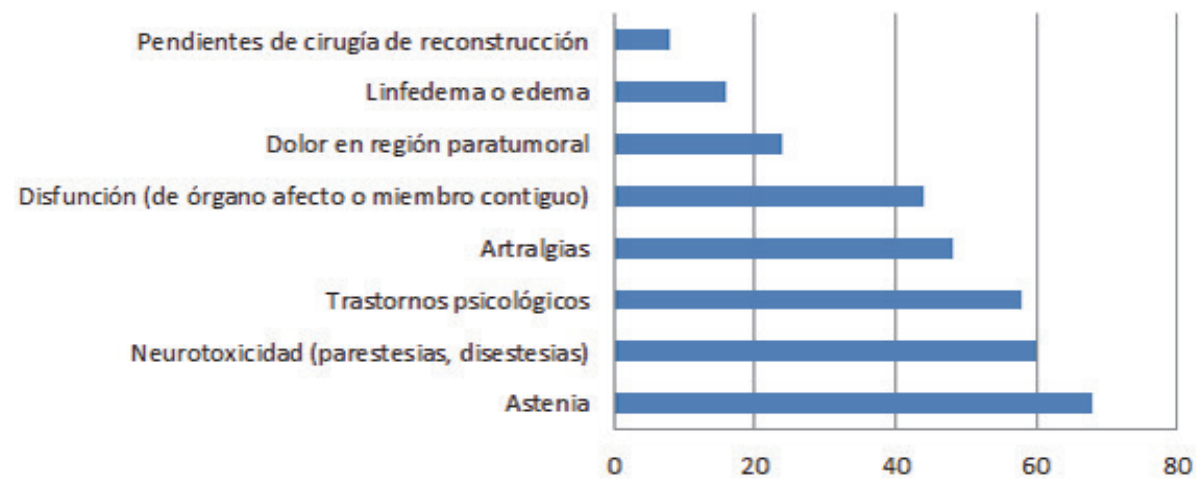

Las secuelas más frecuentes en los supervivientes al cáncer que causaron alta médica tras más de 1 año de incapacidad temporal (IT), eran la astenia o fatiga, las parestesias/ disestesias (Síndrome de mano-pie), los trastornos psicológicos (trastorno del ánimo, síntomas depresivos, ansiedad, déficit de memoria, concentración o atención) y las artralgias. La valoración del alta médica o no declaración de incapacidad permanente se entiende para los grados funcionales 0 y 1.

\section{GRADOS FUNCIONALES 0 y 1 DE VALORACIÓN DEL CÁNCER. (Sobre 4 grados funcionales posibles)}

\section{Grado 0}

Genérica: No hay síntomas y las pruebas complementarias son normales. No sigue tratamiento. Karnofsky $100 \%$. Incluye tumores curados o en remisión completa sin tratamiento ni secuelas. Plena capacidad funcional cotidiana. 
Brazo: Balance articular y muscular completo, fuerza y sensibilidad normales, sin signos de linfedema.

Funcionalidad de órgano afecto: normal, recuperada, completa.

Dolor: No dolor o soportable sin tratamiento.

Psicopatología: no síntomas, no tratamiento.

- Orientaciones clínico-laborales: No se objetivan limitaciones clínico-laborales.

\section{Grado 1}

Genérica: Secuelas leves secundarias a tratamientos oncológicos y de la cirugía oncoplástica, síntomas leves o esporádicos. Sin evidencia de enfermedad oncológica, tumores curados o en remisión completa con secuelas leves, en tratamiento de mantenimiento (p.ej. tamoxifeno). Pruebas complementarias levemente alteradas por las secuelas. Karnofsky $>80 \%$.

Artralgias o Astenia: discreta sin limitación funcional, salvo para actividades intensas y/o prolongadas.

- Orientaciones clínico-laborales: Limitación ligera, solo para actividades de muy altos requerimientos físicos o energéticos o circunstancias específicas de condiciones de trabajo que deben individualizarse en función al proceso concreto, tipo de secuelas y tratamiento administrado y el análisis de las tareas a realizar por la trabajadora. A valorar secuelas de determinados tratamientos y ponerlas en relación con el puesto de trabajo (ej. Inhibidores de aromatasa producen osteopenia...).

Funcionalidad de órgano afecto: normal, recuperada, completa, con discretos síntomas, no necesitando de tratamiento. (Diarreas ocasionales, incontinencia ocasional esporádica, disuria, impotencia, etc.).

Brazo: Balance articular completo que puede ser doloroso en algunos arcos o pérdida de movilidad en rangos poco útiles con balance muscular conservado (4+/5), no atrofias musculares y/o linfedema grado I.

- Orientaciones clínico-laborales: Limitación para requerimientos muy intensos del brazo afecto, manejo de cargas, porteo de grandes pesos, tareas continuadas de esfuerzo en plano superior cefálico, deportes de competición, etc. Valorar miembro dominante.

Psicopatología: Eutimia o síntomas adaptativos muy leves. Atención y concentración en rango útil. Plena capacidad funcional cotidiana. Tratamiento conductual eficaz.

Neurotoxicidad: parestesias y/ o disestesias sin disfunción objetivable, sin dolor manifiesto.

- Orientaciones clínico-laborales: Limitación para actividades de precisión y destreza manual extraordinarias.

Dolor: ocasional agudo o dolor leve continuado que responde a tratamiento.

- Orientaciones clínico-laborales: Impedimento funcional temporal en espera de respuesta terapéutica, según la intensidad con capacidades funcionales limitadas para aquellas actividades o despliegue funcional que acentúen el dolor con funcionalidad respetada para otras.

\section{RECAÍDAS en IT en los 6 meses siguientes tras ALTA de ITs de más de 365 días de duración por Cáncer}

Se consideraron sólo las recaídas en IT por el cáncer, en los 180 días siguientes al alta médica. De los 111 casos, sólo 22 cursaron con recaída en los 6 meses siguientes al alta. 
Así pues, en el 80\% de las altas de casos de cáncer de incapacidades temporales (ITs) de más de 365 días de duración, no hubo recaída en los 6 meses siguientes. Pero si en un $20 \%$ de los casos; el 16\% de estas recaídas fue por disfunciones relacionadas con trastornos psíquicos, neurotoxicidad, artralgias, linfedema, cirugía de reconstrucción, dolor, disfunción del órgano afecto o miembro contiguo a la lesión, o por astenia. El 4\% de las recaídas fue por recidiva tumoral. Una constante en las recaídas por disfunción fue la manifestación del paciente de inadaptación al trabajo al obligado retorno al trabajo al ser dado de alta, por molestias persistentes (Tabla 3) (Fig. 13).

Tabla 3. Recaídas de Altas de procesos de IT por Cáncer que superaron los 365 días.

\begin{tabular}{c|c|c|c}
\hline $\begin{array}{c}\text { Procesos con > 365 días } \\
\text { de IT por Cáncer con Altas }\end{array}$ & $\begin{array}{c}\text { Recaídas de Altas } \\
\text { por Cáncer por Disfunción }\end{array}$ & $\begin{array}{c}\text { Recaídas de Altas } \\
\text { por Cáncer por Recidiva }\end{array}$ & $\begin{array}{c}\text { Recaídas de Altas } \\
\text { por Cáncer Totales }\end{array}$ \\
\hline 111 & 18 & 4 & 22 \\
\hline $100 \%$ & $16,21 \%$ & $3,6 \%$ & $19,81 \%$ \\
\hline
\end{tabular}

Figura 13. Recaídas y No Recaídas, tras Alta procesos de cáncer de más de 365 d. de IT.

\section{RECAÍDAS en IT en los 6 meses siguientes al ALTA de IT > 365 días por CÁNCER}

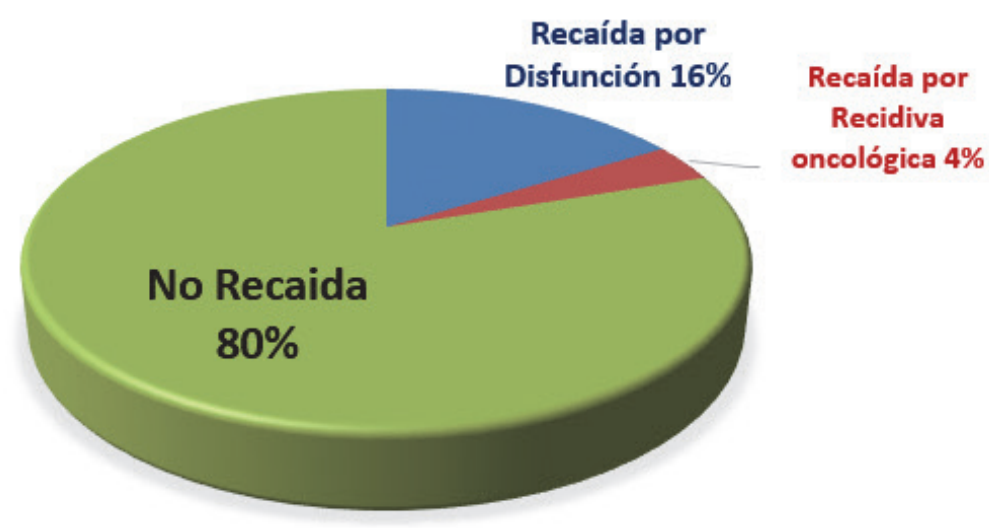

A continuación, describiremos datos referentes a los procesos que causaron recaída por disfunciones diversas en relación al cáncer.

De los 4 casos de recaídas por "recidiva oncológica", 1 fue por neoplasia cerebral, 1 fue por neoplasia de próstata, 1 por linfoma no hodgkin y 1 por cáncer de mama, su presentación fue estocástica, es decir, sin guardar relación con la adaptación al trabajo o no al retorno laboral, y no tratándose de procesos que guardaran relación con riesgos presentes en el trabajo.

\section{RECAÍDAS por "DISFUNCIÓN" de ALTAS de procesos de IT por Cáncer que superaron los 365 días}

De los 18 casos con recaída por disfunción, salvo en dos casos de reconstrucción mamaria, con periodos de alta de 161 y 157 días, el resto de las recaídas se suceden con escasas semanas de actividad laboral, entre el mes y medio y los tres meses, máxime si contemplamos que, al retorno laboral tras más de un año de baja, se sucede en muchos casos el disfrute de las vacaciones (Fig. 14).

Correspondientes a cada uno de los 18 casos de recaída por "disfunción", de forma consecutiva, se recogen en tres tablas, referencias a edad, ocupación, días tras el alta, trastorno psíquico, neurotoxicidad, artralgias, linfedema, cirugía reconstructiva, dolor, disfunción de órgano o miembro contiguo, astenia, y adaptación laboral, correspondientes a cada uno de estos dieciocho casos de forma consecutiva (Tablas 4,5 y 6 ). 
Figura 14. Días transcurridos desde el Alta hasta la Recaída por disfunción, en cada uno de los casos.

\section{Días de Alta hasta Recaída en IT}

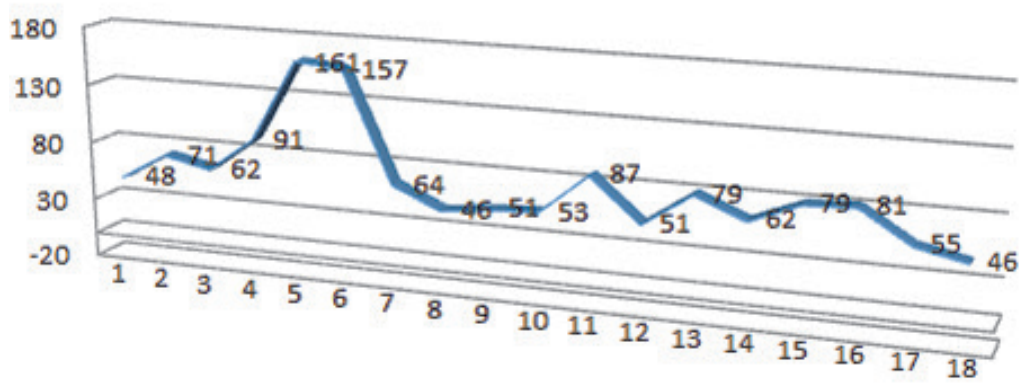

Tabla 4. Listado de recaídas por tipo de cáncer, edad y ocupación.

\begin{tabular}{|c|c|c|c|}
\hline Caso & Tipo Cáncer & Edad & Ocupación \\
\hline 1 & Pulmón & 56 & Auxiliar geriatría \\
\hline 2 & Colorrectal & 58 & Conductor camión \\
\hline 3 & Próstata & 39 & Limpieza industrial \\
\hline 4 & Próstata & 57 & Almacenero \\
\hline 5 & Mama & 56 & Administrativa \\
\hline 6 & Mama & 56 & Administrativa \\
\hline 7 & Mama & 56 & Limpieza \\
\hline 8 & Mama & 52 & Camarera de pisos hotel \\
\hline 9 & Mama & 62 & Administrativa \\
\hline 10 & Mama & 60 & Administrativa \\
\hline 11 & Mama & 45 & Profesora música \\
\hline 12 & Mama & 59 & Tapicera \\
\hline 13 & Mama & 58 & Cuidadora escolar \\
\hline 14 & Mama & 57 & Administrativa \\
\hline 15 & Mama & 56 & Enfermera \\
\hline 16 & Mama & 46 & Administrativa \\
\hline 17 & Mama & 48 & Dependienta \\
\hline 18 & Mama & 54 & Peón industria \\
\hline
\end{tabular}

El balance final del estudio, referenciado en la Tabla 7 , recoge por cada tipo de cáncer, con IT finalizada con alta médica laboral más allá de los 365 días, si hubo recaídas, si estas fueron por recidiva tumoral o por disfunción y en cuántos casos finalmente se declaró Incapacidad Permanente.

En estas recaídas en incapacidad laboral en los 6 meses siguientes de los supervivientes de cáncer con alta médica laboral (ITs de más de 365 días de duración) estaban presentes las disfunciones siguientes: Trastornos psicológicos (incluyendo ansiedad, bajo ánimo, síntomas depresivos, deterioro cognitivo tipo déficit de atención, concentración o memoria) en un $78 \%$, astenia o fatiga en un $44 \%$, neurotoxicidad (parestesias, disestesias) en un 39\%, disfunción de órgano afecto o miembro contiguo en un $39 \%$, artralgias en un $28 \%$, dolor en región paratumoral en un $22 \%$, linfedema o edema en un $22 \%$ y cirugía de reconstrucción en el 11\% de las recaídas siendo en este caso la causa exclusiva de la recaída en incapacidad laboral (Fig. 15). 
Tabla 5. Listado de recaídas disfuncionales por tipo de cáncer, ocupación, días tras el alta, trastorno psíquico, neurotoxicidad, artralgias y linfedema.

\begin{tabular}{|c|c|c|c|c|c|c|c|}
\hline Caso & Tipo Cáncer & Ocupación & $\begin{array}{c}\text { Días tras } \\
\text { el Alta }\end{array}$ & $\begin{array}{l}\text { Trastorno } \\
\text { Psíquico }\end{array}$ & $\begin{array}{l}\text { Parestesias } \\
\text { Disestesias }\end{array}$ & Artralgias & Linfedema \\
\hline 1 & Pulmón & $\begin{array}{l}\text { Auxiliar } \\
\text { geriatría }\end{array}$ & 48 & $\begin{array}{c}\text { Trastorno } \\
\text { Adaptativo }\end{array}$ & No & No & No \\
\hline 2 & Colorrectal & $\begin{array}{l}\text { Conductor } \\
\text { camión }\end{array}$ & 71 & $\begin{array}{c}\text { Trastorno } \\
\text { Adaptativo }\end{array}$ & Sí & No & No \\
\hline 3 & Próstata & $\begin{array}{c}\text { Limpieza } \\
\text { industrial }\end{array}$ & 62 & Ansiedad & No & No & No \\
\hline 4 & Próstata & Almacenero & 91 & No & No & No & No \\
\hline 5 & Mama & Administrativa & 161 & Ansiedad & No & No & No \\
\hline 6 & Mama & Administrativa & 157 & Depresión & No & No & No \\
\hline 7 & Mama & Limpieza & 64 & Ansiedad & No & No & Sí \\
\hline 8 & Mama & $\begin{array}{c}\text { Camarera de } \\
\text { pisos hotel }\end{array}$ & 46 & Depresión & No & No & Sí \\
\hline 9 & Mama & Administrativa & 51 & Ansiedad & Sí & No & No \\
\hline 10 & Mama & Administrativa & 53 & $\begin{array}{c}\text { Trastorno } \\
\text { Adaptativo }\end{array}$ & No & Sí & No \\
\hline 11 & Mama & $\begin{array}{l}\text { Profesora } \\
\text { música }\end{array}$ & 87 & Ansiedad & Sí & Sí & No \\
\hline 12 & Mama & Tapicera & 51 & No & Sí & Sí & No \\
\hline 13 & Mama & $\begin{array}{c}\text { Cuidadora } \\
\text { escolar }\end{array}$ & 79 & No & Sí & No & No \\
\hline 14 & Mama & Administrativa & 62 & $\begin{array}{c}\text { Trastorno } \\
\text { Adaptativo }\end{array}$ & No & No & No \\
\hline 15 & Mama & Enfermera & 79 & Depresión & Sí & No & No \\
\hline 16 & Mama & Administrativa & 81 & No & No & Sí & Sí \\
\hline 17 & Mama & Dependienta & 55 & Ansiedad & No & Sí & Sí \\
\hline 18 & Mama & Peón industria & 46 & No & Sí & No & No \\
\hline
\end{tabular}

Figura 15. Disfunciones presentes en la valoración médica de la recaída en IT, por trastornos funcionales. (No por recidiva tumoral).

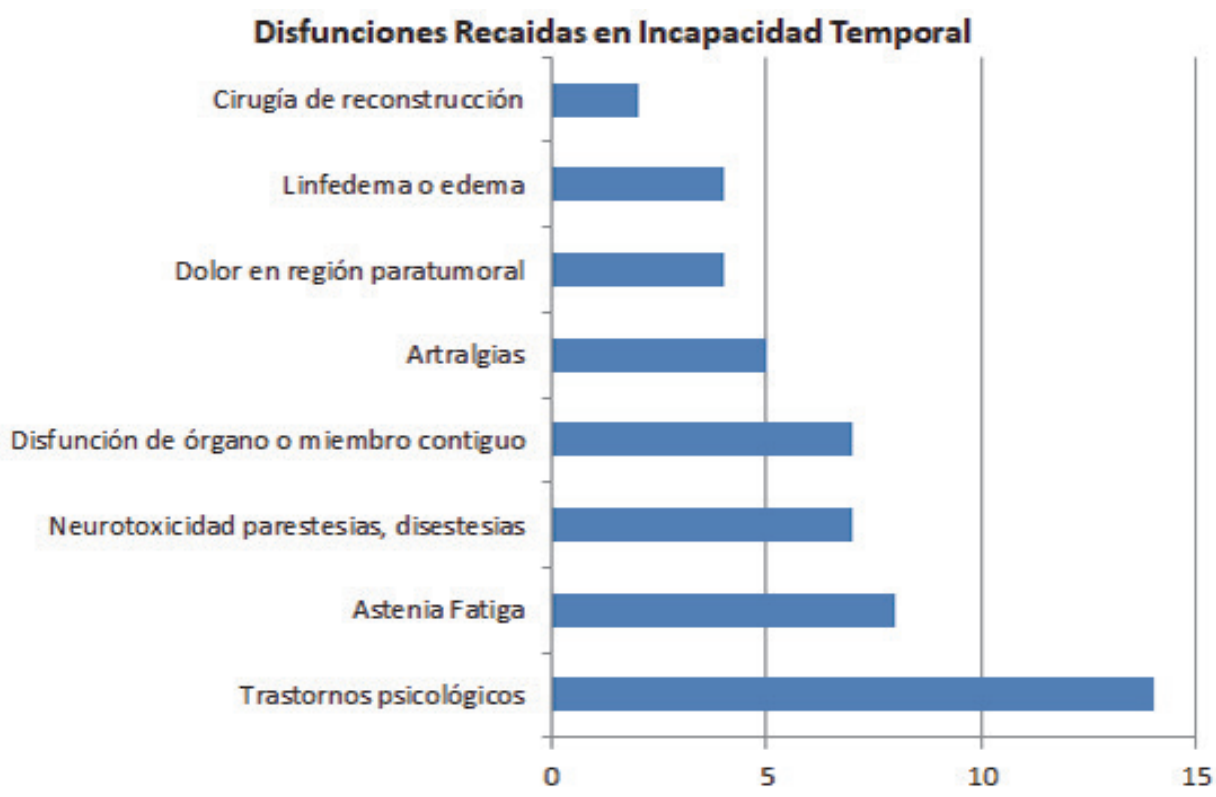


Tabla 6. Listado de recaídas disfuncionales por tipo de cáncer, ocupación, cirugía, dolor, disfunción de órgano o miembro contiguo, astenia, y adaptación laboral.

\begin{tabular}{|c|c|c|c|c|c|c|c|}
\hline Caso & Tipo Cáncer & Ocupación & Cirugía & Dolor & Disfunción & Astenia & $\begin{array}{c}\text { Adaptación } \\
\text { Laboral }\end{array}$ \\
\hline 1 & Pulmón & $\begin{array}{l}\text { Auxiliar } \\
\text { geriatría }\end{array}$ & No & No & $\begin{array}{l}\text { Disfunción } \\
\text { Respiratoria }\end{array}$ & Sí & No \\
\hline 2 & Colorrectal & $\begin{array}{l}\text { Conductor } \\
\text { camión }\end{array}$ & No & $\begin{array}{c}\text { Dolor } \\
\text { Abdominal } \\
\end{array}$ & $\begin{array}{c}\text { Incontinencia } \\
\text { ocasional }\end{array}$ & Sí & No \\
\hline 3 & Próstata & Limpieza & No & $\begin{array}{c}\text { Dolor } \\
\text { Pélvico y } \\
\text { MMII }\end{array}$ & Urinaria & Sí & No \\
\hline 4 & Próstata & Almacenero & No & $\begin{array}{c}\text { Dolor } \\
\text { Pélvico }\end{array}$ & Urinaria & No & No \\
\hline 5 & Mama & Administrativa & PróteSís & No & No & Sí & No \\
\hline 6 & Mama & Administrativa & PróteSís & No & No & No & No \\
\hline 7 & Mama & Limpieza & No & No & No & Sí & No \\
\hline 8 & Mama & $\begin{array}{c}\text { Camarera de } \\
\text { pisos hotel }\end{array}$ & No & No & No & No & No \\
\hline 9 & Mama & Administrativa & No & No & No & Sí & No \\
\hline 10 & Mama & Administrativa & No & No & No & No & No \\
\hline 11 & Mama & $\begin{array}{l}\text { Profesora } \\
\text { música }\end{array}$ & No & No & No & No & No \\
\hline 12 & Mama & Tapicera & No & No & Brazo mano & No & No \\
\hline 13 & Mama & $\begin{array}{c}\text { Cuidadora } \\
\text { escolar }\end{array}$ & No & No & Brazo & no & No \\
\hline 14 & Mama & Administrativa & No & No & No & Sí & No \\
\hline 15 & Mama & Enfermera & No & No & Brazo & No & No \\
\hline 16 & Mama & Administrativa & No & No & No & No & No \\
\hline 17 & Mama & Dependienta & No & Sí & No & No & No \\
\hline 18 & Mama & Peón industria & No & No & No & Sí & No \\
\hline
\end{tabular}

Tabla 7. Datos globales de altas tipo cáncer y recaídas e IP.

\begin{tabular}{l|c|c|c|c|c}
\hline \multicolumn{1}{|c|}{ TIPO DE CÁNCER } & $\begin{array}{c}\text { No Procesos } \\
\text { de Cáncer con } \\
\text { ALTA }\end{array}$ & $\begin{array}{c}\text { RECAÍDAS } \\
\text { por Tipo } \\
\text { de Cáncer }\end{array}$ & $\begin{array}{c}\text { RECAÍDAS } \\
\text { por Disfunción }\end{array}$ & $\begin{array}{c}\text { RECAídAS } \\
\text { por Recidiva }\end{array}$ & $\begin{array}{c}\text { Incapacidad } \\
\text { Permanente }\end{array}$ \\
\hline Melanoma & $\mathbf{1}$ & 0 & 0 & 0 & 0 \\
\hline Neo Gástrica & $\mathbf{1}$ & 0 & 0 & 0 & 0 \\
\hline Neo Pulmón & $\mathbf{1}$ & $\mathbf{1}$ & $\mathbf{1}$ & 0 & $\mathbf{1}$ \\
\hline Neo Útero & $\mathbf{2}$ & 0 & 0 & 0 & 0 \\
\hline Neo Vejiga & $\mathbf{3}$ & 0 & 0 & 0 & 0 \\
\hline Neo Tiroides & $\mathbf{3}$ & 0 & 0 & 0 & 0 \\
\hline Neo Boca Orofaringe & $\mathbf{4}$ & 0 & 0 & 0 & 0 \\
\hline Neo Próstata & $\mathbf{4}$ & $\mathbf{3}$ & $\mathbf{2}$ & $\mathbf{1}$ & $\mathbf{2}$ \\
\hline Neo Cerebral & $\mathbf{5}$ & $\mathbf{1}$ & 0 & $\mathbf{1}$ & $\mathbf{1}$ \\
\hline Neo Colorrectal & $\mathbf{1 1}$ & $\mathbf{1}$ & $\mathbf{1}$ & 0 & $\mathbf{1}$ \\
\hline Linfomas y Leucemia & $\mathbf{1 3}$ & $\mathbf{1}$ & 0 & $\mathbf{1}$ & $\mathbf{1}$ \\
\hline Neo Mama & $\mathbf{6 3}$ & $\mathbf{1 5}$ & $\mathbf{1 4}$ & $\mathbf{1}$ & $\mathbf{7}$ \\
\hline TODOS & $\mathbf{1 1 1}$ & $\mathbf{2 2}$ & $\mathbf{1 8}$ & $\mathbf{4}$ & $\mathbf{1 3}$ \\
\hline
\end{tabular}


De las recaídas que se sucedieron en los 6 meses siguientes al alta en un 59\% supusieron la declaración de incapacidad permanente, frente al $41 \%$ que supuso prorrogar la IT hasta su fin (Fig. 16).

En todas las recaídas los trabajadores refirieron se incorporaron al trabajo sin adaptación transitoria, en las mismas condiciones y con las mismas tareas que tenían antes de tener el cáncer. De hecho, fue uno de sus argumentos como causa de la imposibilidad de continuar trabajando, incorporándose al trabajo, hasta que no pudieron más.

Figura 16. Recaídas en Incapacidad Temporal que concluyeron en Incapacidad Permanente.

\section{Recaídas en los $6 \mathrm{~m}$ y declaraciones de IP}

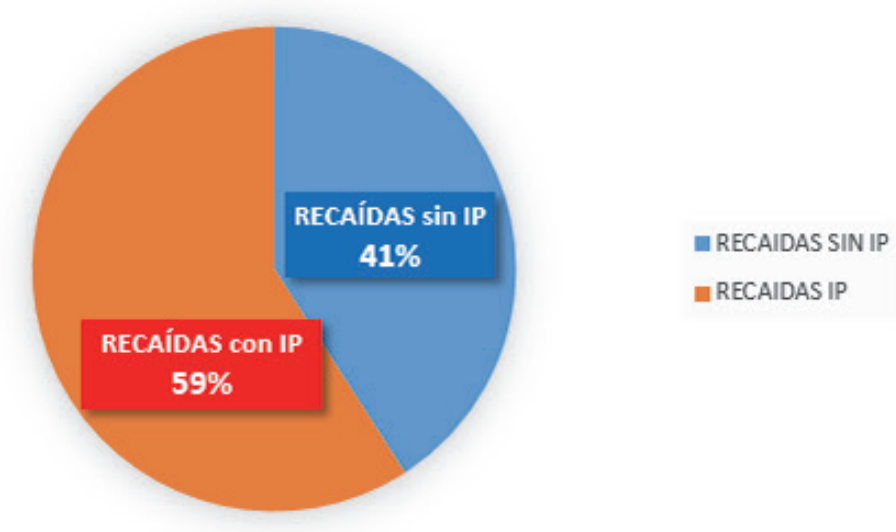

\section{Conclusiones del estudio bajas de más de 365 días por cáncer}

Los procesos estudiados, son aquellos casos de supervivientes al cáncer, con incapacidad prolongada, que permanecieron más de 365 días en incapacidad temporal (IT). Analizando los casos con alta médica se comprueba la presencia en un $81 \%$ de los casos de secuelas que, aun no siendo incapacitantes, pueden comportar un retorno laboral dificultoso en el caso de no disponer de adaptación laboral en la fase inmediata de reincorporación laboral, o ser causa de presentismo, o de bajo rendimiento o causar perjuicio para su salud si el trabajo ocasiona un agravamiento de las mismas. Estas secuelas presentes al alta constituyen una "aptitud sobrevenida", pues no se da en estos supuestos una restitución funcional ad integrum al retorno laboral, que sólo estaba presente en un reducido porcentaje del 19\%.

En un $16 \%$ de los procesos analizados de cáncer con alta médica tras incapacidad prolongada hubo recaída por disfunciones en relación con el cáncer y sus secuelas en el periodo de los 6 meses siguientes, lo que es significativo. Estos casos de recaída en IT analizados sólo referencian recaídas en los 6 meses siguientes, no valoran las posibles recaídas, fuera de este plazo, más allá de estos 180 días, que añadirían datos para evaluar de forma completa un retorno laboral efectivo. Pero hasta la formalización del vMapa de Incapacidad Laboral en España" entendido como archivo de datos que permita explotación actualizada, activa e inmediata, esto no es posible.

Los cánceres que causan alta médica tras larga incapacidad temporal laboral son aquellos de buena evolución y buen pronóstico, por ello destaca el cáncer de mama sobre cualquier otro.

La edad de los afectados se concentra en edades comprendidas entre los 50 y los 60 años, colectivo laboral más vulnerable a la estabilidad laboral y más proclive a la comorbilidad y dificultad en el mantenimiento del retorno laboral efectivo.

Las recaídas por disfunciones derivadas de las secuelas del cáncer, que no por recidiva del tumor, se sucedieron de forma temprana, y se dieron en 16 casos (73\% de las 
recaídas por disfunción) entre los 45 y los 91 días posteriores al alta médica, lo que constata un retorno laboral deficiente.

Las secuelas más frecuentes en los supervivientes al cáncer que causaron alta médica tras más de 1 año de incapacidad temporal (IT), eran la astenia o fatiga, las parestesias/ disestesias (Sdre. mano-pie), los trastornos psicológicos (ansiedad, bajo ánimo, síntomas depresivos, déficit de atención, concentración o memoria) y las artralgias.

Todas las recaídas por recidiva tumoral finalizaron en declaración de incapacidad permanente,

En referencia a las disfunciones más frecuentes y presentes en el resto de las recaídas en incapacidad laboral (exceptuando a las recidivas tumorales), de estos procesos que iniciaron retorno laboral, fueron por trastornos psicológicos (ansiedad, bajo ánimo, síntomas depresivos, déficit de atención, concentración o memoria), astenia o fatiga, parestesias/disestesias y artralgias. Y en un 50\% de estas recaídas se consideró la incapacidad permanente, lo que supone un fracaso de la intención de retorno laboral inicial.

\section{CONCLUSIONES FINALES. APTITUD SOBREVENIDA Y RETORNO AL TRABAJO TRAS BAJA PROLONGADA POR CÁNCER}

Las incapacidades temporales por cáncer son habitualmente muy prolongadas, como prolongadas son sus secuelas. Las bajas por cáncer en cuanto a su duración estándar de la Incapacidad Temporal, difieren para cada tipo de neoplasia, aunque acostumbra en general a superar los 6 meses de baja, y un 30\% de los procesos de Incapacidad Temporal por cáncer mantienen la baja y alcanzan o sobrepasan los 365 días, procesos que son sobre los que se centró el presente estudio. Las Neoplasias por capítulos diagnósticos son la tercera causa en alcanzar los 365 días de baja, suponen el 13,25\% de los procesos con bajas que llegan al año ${ }^{1}$.

La incapacidad laboral prolongada por cáncer supone para el trabajador, que aún superado el proceso de tratamiento intenso y con una buena respuesta al mismo, un deterioro de su motivación, de su satisfacción personal, de la seguridad en sí mismo y de su sentimiento de sentirse capacitado, todo ello en un largo proceso que ha supuesto como secuelas una fragilidad psicológica, derivada de la lucha contra una enfermedad con compromiso vital, y sometimiento a tratamientos intensos con merma añadida de su capacidad y resistencia física, en menor o mayor medida, y una menor capacidad de adaptación a nuevas exigencias por el desgaste causado por el largo e intenso periodo de tratamiento y la incertidumbre vital. El prolongado alejamiento del trabajo ha supuesto una pérdida de las habilidades profesionales, una desconexión con las actualizaciones o cambios que pueden haberse producido en su trabajo y una inseguridad sobre el retorno en cuestionarse si será o no capaz de rendir como antes del cáncer y sobre el apoyo o rechazo que pueda recibir al retorno al trabajo ${ }^{3}$.

El trabajador superviviente al cáncer al concluir el período de incapacidad destinado a la curación o la mejoría funcional que permita realizar su trabajo, suele presentar una serie de disfunciones o mermas en su "aptitud" laboral, que denominamos "aptitud sobrevenida", que aun no configurando una incapacidad ni un no apto, si constituyen un riesgo en el inmediato retorno laboral, riesgo que es preciso considerar para prevenir recaídas en la incapacidad o finalmente el abandono del trabajo. Esta situación tiene un carácter transitorio y por ello las medidas de adaptación al puesto que se implementen serán eficaces en el período inicial de vuelta al trabajo.

El trabajador superviviente al cáncer puede retornar al trabajo, pero debemos de ser conscientes que una Aptitud Sobrevenida que modifica su capacidad funcional previa y con unos nuevos riesgos para su salud y frente al trabajo (Fig. 17). 
Figura 17. Retorno al trabajo tras larga baja/incapacidad laboral por cáncer. Aptitud sobrevenida.

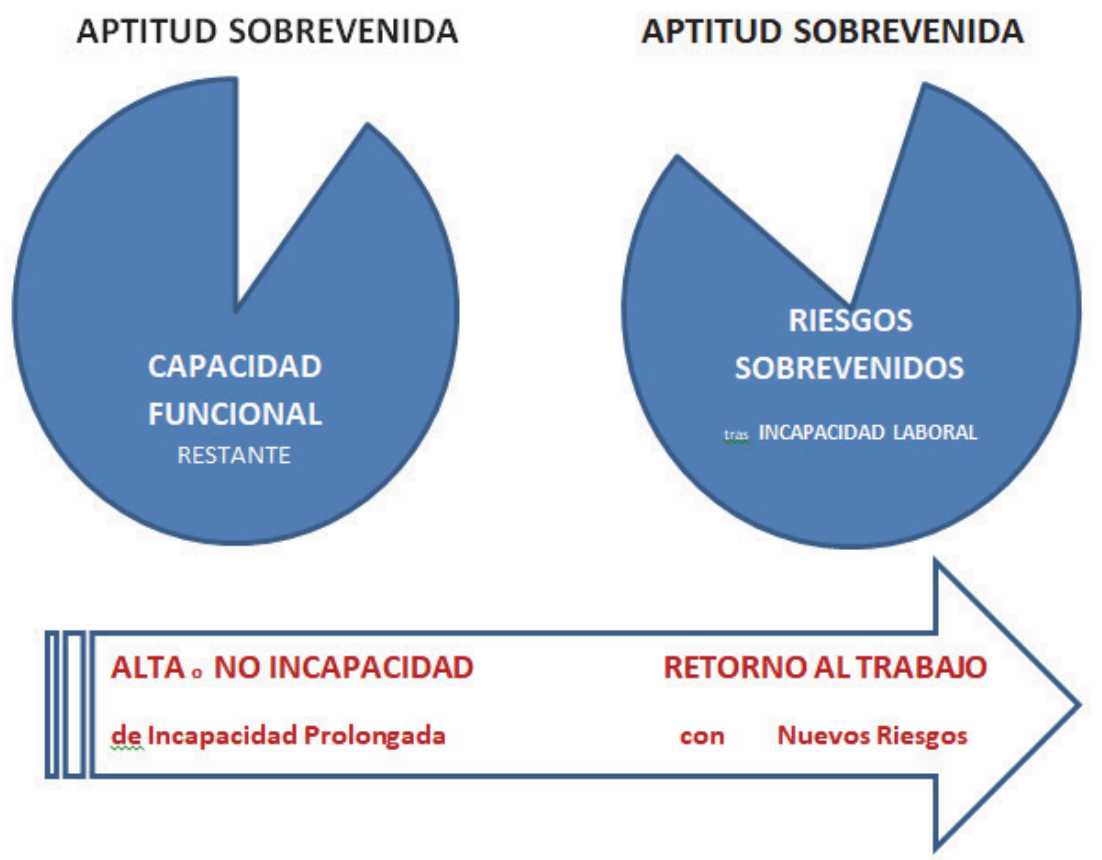

Es decir, el retorno al trabajo tras el cáncer supone abordar una nueva situación que necesita de un periodo de adaptación obligado para facilitar la recuperación laboral, sin riesgo y de forma saludable y continuada. Evitando el impacto de la reintegración laboral como si nada hubiera acontecido o como si se tratara de una reintegración con plena recuperación de las capacidades funcionales, como las que mantenía previamente, superando las barreras al regreso al trabajo ${ }^{4,5}$.

La consideración y abordaje de la "Aptitud Sobrevenida" garantiza la salud laboral, busca el mayor rendimiento en el trabajo, la mayor satisfacción del trabajador, pretende el retorno laboral eficaz y duradero, evitando el presentismo, las recaídas, el despido o la dimisión personal con abandono del trabajo. Reincorporar al trabajo al superviviente de cáncer y hacerlo de forma eficaz, que perdure, y que se haga sin perjuicio de su salud contribuye a la sostenibilidad del sistema económico y del sistema de seguridad social, pero primero y principal contribuye a que el superviviente de cáncer sobreviva económicamente y se reincorpore al trabajo de forma efectiva y saludable retorne a su vida anterior.

Los datos de retorno laboral y recaídas del estudio realizado se circunscriben a una parte del territorio nacional, Gipuzkoa, en un período de tiempo concreto, y no más allá de los 6 meses siguientes al alta. Este estudio de apoyo en el conocimiento de las disfunciones presentes al alta del trabajador superviviente al cáncer, es sin embargo limitado, pero pone en evidencia la necesidad urgente de que la Seguridad Social ponga en marcha el compromiso de elaborar un Mapa de la Incapacidad laboral en España, para con datos analizar el verdadero impacto que el cáncer ocasiona a la población trabajadora. Obviamente sin datos sin análisis de los mismos no se conoce lo que está ocurriendo y no pueden valorarse cualquier propuesta de mejora. Manejando además el indicador de incapacidad o de no retorno como un indicador de gestión sanitario, indicador de resultado, indicador social, indicador de salud laboral. Así mismo es preciso elaborar un Plan estratégico de protección integral del superviviente del cáncer, para facilitar la reintegración laboral.

Del análisis de la aptitud sobrevenida y las dificultades al retorno laboral y así como del estudio de las referencias bibliográficas que se referencian al final del artículo, puede concluirse la necesidad un periodo de adaptación al retorno laboral, para que trabajar no suponga un reto insalvable. 
El trabajador en el momento de afrontar la reincorporación expresa la dificultad de una incorporación a plena exigencia de rendimiento. Una reincorporación con reducción de la carga de trabajo podría acortar los periodos de baja, si ello fuera posible, y propiciar una reincorporación laboral saludable. Es llamativo que en las recaídas en incapacidad temporal (excluyendo las recaídas por recidiva tumoral u otra complicación grave) el trabajador se queje de la impotencia para trabajar y acuse del fracaso de la vuelta al trabajo el no haber tenido una adaptación gradual y paulatina, en la mayoría de las ocasiones referido o por la fatiga y /o los trastornos psicológicos (incluyendo la desmotivación) que fueron el detonante del fracaso en la reincorporación al trabajo ${ }^{6}$.

Se precisa un apoyo psicológico a lo largo de todo el proceso de tratamiento y también en la etapa final para fomentar la actitud de afrontamiento y las modificaciones de conducta necesarias para ello, máxime cuando observamos que una de las disfunciones más frecuentes tanto al momento del retorno como en las recaídas, son los trastornos psicológicos, que precisan de la "reconstrucción psicológica" del superviviente. Teniendo en cuenta que los trastornos psicológicos predominan en las recaídas y así mismo ocupan un lugar preferente en las secuelas disfuncionales al alta, como hemos señalado, deben de vigilarse los factores psicosociales y por supuesto los riesgos psicosociales si queremos garantizar una vuelta al trabajo que perdure con eficiencia ${ }^{7,8,9}$.

Es necesario no minusvalorar algunos de los síntomas frecuentes como la fatiga/ astenia, las artralgias, los trastornos sensitivos o los problemas de atención, concentración o memoria presentes al final del proceso y en el momento del retorno como secuelas, que son difíciles de objetivar y cuantificar desde la perspectiva médico evaluadora, pero han de ser tenidos en cuenta por cuanto suponen una merma de las capacidades funcionales del trabajador y un riesgo adquirido, que con correctas medidas transitorias y tempranas de adaptación de las tareas laborales y apoyo en el proceso de reingreso al trabajo pueden conseguir finalmente un rendimiento laboral correcto $^{10}$.

Abordar en la empresa la acogida del trabajador apoyando su recepción, y facilitando una gradual reintegración laboral. En esta línea debiera de normarse el alta parcial al trabajo, bien reduciendo la jornada o la intensidad de las cargas físicas o psicológicas que requiere el trabajo, durante el proceso transitorio de integración y adaptación paulatina al trabajo. A la par que establecer medidas fiscales o en la cotización que incentiven a la empresa que logre el retorno continuado y saludable al trabajo, del trabajador con cáncer.

Intervención multidisciplinar y comunicación compartida entre los profesionales, pues en la valoración de la incapacidad de estos procesos se constata la falta de comunicación entre la parte atencional sanitaria, la gestión de la prestación (económica) y el ámbito laboral.

Es necesario fomentar medidas de rehabilitación o restauración de las capacidades mermadas por el cáncer. Así como programas de formación profesional específicos para la actualización o mejora de sus competencias laborales ${ }^{11}$.

Es preciso el establecimiento de las políticas de retorno al trabajo de los supervivientes al cáncer multidisciplinarias y la reevaluación de las intervenciones implementadas ${ }^{12,13,14}$.

Es obligado la mejora del conocimiento por parte del INSS de las tareas para las que se considera la capacidad/incapacidad laboral tras baja prolongada por cáncer con el uso de la Ficha Ocupacional ${ }^{15}$. Mejorando la calidad decisoria y el carácter preventivo de las mismas.

Todo lo anterior contribuye a plantear propuestas para abordar la aptitud sobrevenida tras el largo proceso de tratamiento de los supervivientes de cáncer, y facilitar un retorno laboral eficaz. 


\section{PROPUESTAS para un retorno laboral eficaz del trabajador superviviente del cáncer}

- Elaboración del Mapa de Incapacidad Laboral para conocer el verdadero impacto socio laboral del cáncer, y analizar las medidas para fomentar un retorno al trabajo eficaz.

- Considerar la Incapacidad (el no retorno) como un indicador de salud laboral, un indicador de resultado en salud, un indicador sanitario de calidad en la gestión sanitaria.

- Elaborar un Plan estratégico de protección integral del superviviente del cáncer, para facilitar la reintegración laboral. La capacidad real de trabajar, depende múltiples factores, unos médicos, otros laborales y otros sociales.

- Consideración preventiva de las decisiones del retorno al trabajo, que considere el tránsito o período obligado de adaptación al trabajo tras un alta médica. Garantizar la bioseguridad en lo laboral.

- Mejora de los sistemas de calificación de la incapacidad/capacidad laboral con una actualización en las consideraciones evaluadoras del cáncer y sus secuelas (Manual de Actuación Médico Evaluadora), un mejor y más exacto conocimiento del trabajo que se realiza, mediante el uso de la Ficha Ocupacional y una reforma del órgano valorador Equipo de Valoración de incapacidades, tanto en su composición, que debe ser fundamentalmente técnica y con representación exclusiva de vocales con conocimientos en medicina evaluadora y salud laboral y sobre conocimientos técnicos del trabajo, requerimientos y condiciones laborales, como en sus competencias, abordando las reclamaciones que sustenten en la controversia entre el no apto y la no incapacidad laboral.

- Mejora de la comunicación entre agentes implicados atención sanitaria, gestores de la incapacidad y el mundo del trabajo.

- Incorporación parcial al trabajo (Altas Parciales) tras incapacidad. Facilitar la reincorporación parcial, progresiva o gradual, bien en horario, bien en intensidad de las cargas de trabajo, promoviendo una reintegración más efectiva evitando recaídas. En la etapa inicial de retorno facilitar horarios flexibles o reducción horaria que favorezcan la conciliación familiar. Tras un proceso que obligadamente supone una nueva visión vital y un significado nuevo de la importancia y trascendencia del trabajo, con mayor necesidad del apoyo familiar.

- Facilitar la adaptación laboral efectiva ante la "Aptitud sobrevenida", considerando la nueva situación del trabajador reincorporado y la presencia de nuevos riesgos contraídos, riesgos en su salud y riesgos del trabajo para su salud.

- Consideración del retorno laboral del superviviente al cáncer como "Trabajador Sensible".

- Evitar controversias entre alta médica y no apto, yendo más allá de lo prestacional al extender el alta médica, con concordancia decisoria, en ese continuo que debiera existir entre capacidad y aptitud.

- Mayor detección y protección de los factores psicosociales en el trabajo y riesgos psicosociales, pues una de las secuelas más habituales del superviviente de cáncer es la fragilidad y el deterioro psicológico, que potenciarían el riesgo.

- Mejoras en la organización, condiciones y clima laboral, que fomenten la satisfacción laboral, y el sentimiento de apoyo al retorno.

- Incentivación a las empresas para promover el retorno de trabajadores con cáncer. Medidas que supongan beneficios fiscales y reducción de cotizaciones de empresa.

- Programas Formación y Rehabilitación para potenciar la reinserción laboral del trabajador tras el cáncer. 


\section{REFERENCIAS BIBLIOGRÁFICAS}

1. Vicente Pardo José Manuel, López-Guillén García Araceli. Cáncer en población trabajadora. Incapacidad y riesgo de exclusión laboral y social. Medicina Seguridad Trabajo. 2018 Dic; 64(253): 354-378. Disponible en: http://scielo.isciii.es/scielo.php?script=sci_arttext\&pid=S0465-546X2018000400354\&lng=es.

2. Molina, Raquel \& Feliu, Jaime. (2011). La reinserción laboral: un nuevo reto en el paciente con cáncer. Psicooncología. 8(1): 4. DOI: 10.5209/rev_PSIC. 2011.v8.n1.4. Disponible en: https://revistas.ucm.es/ index.php/PSIC/article/view/PSIC1111120045A

3. Endo, M., Haruyama, Y., Takahashi, M., Nishiura, C., Kojimahara, N., \& Yamaguchi, N. (2015). Returning to work after sick leave due to cancer: a 365-day cohort study of Japanese cancer survivors. Journal of Cancer Survivorship: Research and Practice, 10(2), 320-329. doi: 10.1007/s11764-015-0478-3. Disponible en: https://doi.org/10.1007/s11764-015-0478-3

4. Kiasuwa Mbengi, Régine et al. "Barriers and opportunities for return-to-work of cancer survivors: time for action--rapid review and expert consultation.” Systematic Reviews vol. 535.24 Feb. 2016, doi: 10.1186/ s13643-016-0210-z. Disponible en: https://doi.org/10.1186/s13643-016-0210-z

5. Endo M, Haruyama Y, Muto G, et al. Work Sustainability Among Male Cancer Survivors After Returning to Work, Journal of Epidemiology, 2018, Volume 28, Issue 2, Pages 88-93. Disponible en: https://doi. org/10.2188/jea.JE20160152

6. Wolvers, MDJ, Leensen, MCJ, Groeneveld, IF et al. Longitudinal Associations Between Fatigue and Perceived Work Ability in Cancer Survivors. J Occup Rehabil (2018). Disponible en: https://doi.org/10.1007/ s10926-018-9814-6

7. Schumacher L, Armaou M, Rolf $\mathrm{P}$, et al. Usefulness and engagement with a guided workbook intervention (WorkPlan) to support work related goals among cancer survivors. BMC Psychol 2017;5:34. Disponible en: https://doi.org/10.1186/s40359-017-0203-2

8. Fitch, MI, Nicoll, I. Returning to work after cancer: Survivors', caregivers', and employers' perspectives. Psycho-Oncology. 2019; 792-8. Disponible en: https://doi.org/10.1002/pon.5021

9. Vicente Pardo José Manuel, López-Guillén García Araceli. Los factores psicosociales como predictores pronósticos de difícil retorno laboral tras incapacidad. Medicina y Seguridad del Trabajo. 2018 Mar: 64(250): 50-74. Disponible en: http://scielo.isciii.es/scielo.php?script=sci_arttext\&pid=S0465546 X2018000100050\&lng=es.

10. Wolvers, MDJ et al. "Predictors for earlier return to work of cancer patients". Journal of Cancer Survivorship: Research and Practice vol. 12,2 (2017): 169-177. Doi: 10.1007/s11764-017-0655-7. Disponible en: https://doi.org/10.1007/s11764-017-0655-7

11. European Agency for Safety and Health at Work - EU-OSHA. Rehabilitation and return to work after cancer. Literature review European Risk Observatory. Disponible en: https://osha.europa.eu/en/toolsand-publications/publications/rehabilitation-and-return-work-after-cancer-literature-review

12. Volker Arndt, Lena Koch-Gallenkamp, Heike Bertram, Andrea Eberle, Bernd Holleczek, Ron Pritzkuleit, Mechthild Waldeyer-Sauerland, Annika Waldmann, Sylke Ruth Zeissig, Daniela Doege, Melissa S. Y Thong \& Hermann Brenner (2019) Return to work after cancer. A multi-regional population-based study from Germany, Acta Oncologica. Disponible en: https://doi.org/10.1080/0284186X.2018.1557341

13. Caron Maryse, Durand Marie-José, Tremblay Dominique, "Interventions pour le retour et le maintien au travail après un cancer : revue de la littérature ", Santé Publique, 2017/5 (Vol. 29), p. 655-664. Disponible en: https://www.cairn.info/revue-sante-publique-2017-5-page-655.htm

14. López-Guillén García Araceli, Vicente Pardo José Manuel. Necesidad de políticas de retorno al trabajo tras incapacidad laboral prolongada, en materia de seguridad social. Medicina y Seguridad del Trabajo. 2018 Dic [citado 2019 Mayo 13] ; 64(253): 379-401. Disponible en: http://scielo.isciii.es/scielo.php?script=sci_ arttext\&pid=S0465-546X2018000400379\&lng=es

15. Vicente Pardo, José Manuel. El Informe Médico de Valoración de la Capacidad Laboral y la Ficha de Evaluación de la Capacidad Laboral una nueva herramienta en la gestión y valoración de las situaciones de incapacidad. Disponible en: http://www.lmee-svmt.org/panel-lmee-svmt/tinymce/ plugins/filemanager/uploads/20130924-Actualizacion/131004_DrVicente_Informe_Medico_ Valoracion_Capacidad_Laboral.pdf 